\title{
Paisaje natural y envejecimiento saludable en el lugar: el caso del Parque Nacional Cumbres de Monterrey (México)
}

\author{
Natural landscape and healthy ageing in place: \\ the case of the Cumbres de Monterrery National Park in Mexico
}

\section{Diego Sánchez-González}

diego.sanchezg@uam.es

Departamento de Geografía

Universidad Autónoma de Madrid (España)

\section{Lydia Marcela Adame Rivera \\ lydia.adamerv@@uanl.edu.mx \\ Facultad de Arquitectura}

Universidad Autónoma de Nuevo León (México)

\author{
Vicente Rodríguez-Rodríguez \\ vicente.rodriguez@cchs.csic.es \\ Instituto de Economía, Geografía y Demografía \\ CSIC (España)
}

\section{Resumen}

La investigación analiza los factores del paisaje natural cotidiano que favorecen el envejecimiento saludable en el lugar y la calidad de vida de las personas mayores residentes en los límites del Parque Nacional Cumbres de Monterrey (México). La metodología ha consistido en la utilización de métodos como fotovoz y mapas mentales aplicados a grupos de discusión por personas mayores, 
encuestas y Sistemas de Información Geográfica. Los resultados indican que la exposición a elementos naturales del paisaje, como árboles y flores, contribuye al envejecimiento saludable en el lugar, favoreciendo las actividades cotidianas, como relaciones sociales y ocio, mejoran la percepción de la salud y disminuyen las necesidades de ayuda. Asimismo, se muestra que el paisaje natural cotidiano, como elemento simbólico de la identidad ambiental, está asociado a la presencia de recuerdos y vivencias del parque, frecuencia de visitas, grado de conservación de la vegetación autóctona, la proximidad al parque, la práctica de ocio y las relaciones sociales. También, el estudio confirma la importancia de las implicaciones de los paisajes naturales en la calidad de vida de la población, en especial, de las personas mayores, por sus beneficios terapéuticos y simbólicos. Además, se propone impulsar esta línea investigación y generar políticas sostenibles de calidad de vida para favorecer el desarrollo y protección de los paisajes naturales en la región.

Palabras clave: paisajes naturales; envejecimiento saludable; identidad ambiental; calidad de vida; Gerontología Ambiental.

\begin{abstract}
The research analyzes the factors of daily natural landscape that support healthy aging in place and the quality of life of elderly residents in the limits of the National Park "Cumbres" of Monterrey (México). The methodology involved the use of methods such photovoice and mental maps applied to discussion groups of elderly, surveys and Geographic Information Systems. The results indicate that exposure to natural landscape features such as trees and flowers, contributes to healthy aging in place, favoring quotidian activities such as leisure and social relations, improve the perception of health and reduce the need for aid. It also shows that the daily natural landscape as a symbolic element of the environmental identity, is associated with the presence of memories and experiences of the park, visit frequency, degree of conservation of native vegetation, proximity to the park, practicing leisure and social relations. Also, the study confirms the importance of the implications of natural landscapes in the quality of life of the population, especially the elderly, for their therapeutic and symbolic benefits. In addition, it aims to boost this line research and generate sustainable quality of life policies to encourage the development and protection of natural landscapes in the region.
\end{abstract}

Key words: natural landscapes; healthy aging; environmental identity; quality of life; Environmental Gerontology. 


\section{Introducción}

En América Latina el proceso de envejecimiento demográfico se desarrolla en un contexto de urbanización en crisis social (pobreza, exclusión social) y de cambio climático. En el siglo XXI se plantea el reto de crear entornos amigables y sostenibles para envejecer en el lugar (OMS, 2007).

En el envejecimiento se produce una disminución de las capacidades psicofísicas y un aumento del tiempo de estancia en el lugar (vivienda y colonia), donde los ambientes naturales próximos adquieren relevancia en el mantenimiento de las actividades de la vida cotidiana de las personas mayores, reduciendo el riesgo de la reubicación (Peace et al., 2006). Asimismo, recientes investigaciones señalan la importancia del componente natural en el envejecimiento saludable en el lugar, a través del incremento de las actividades cotidianas y sus efectos tangibles en la salud y, en general, la calidad de vida (Gueguen y Stefan, 2014). También, las áreas verdes arboladas contribuyen a generar entornos estimulantes y atractivos para envejecer en el lugar, que elevan de manera positiva la satisfacción en su entorno (Takano et al., 2002). A la inversa, la ausencia de áreas verdes repercute negativamente en el envejecimiento activo en el lugar, lo que se traduce en una disminución de actividades cotidianas al aire libre (ocio, recreación, relaciones sociales) (Kaplan y Kaplan, 2003; Peace et al., 2006). Al respecto, se conoce escasamente cómo las personas mayores experimentan el entorno natural próximo, así como su influencia en las oportunidades de afrontar desafíos cotidianos en el envejecimiento (Krause, 2004).

En las últimas décadas la literatura ha reflejado el interés creciente por conocer la influencia de la naturaleza en la construcción de la identidad personal y social en el envejecimiento (Clayton, 2003; Donno, Webb y Richardson, 2010; Whithmarsh y O’Neill, 2010). Sin embargo, sigue siendo escasa la comprensión de la identidad ambiental en el envejecimiento saludable (Kahn et al. 2009; Olivos y Aragonés, 2011; Yen et al. 2014; Sánchez-González, 2014). Así, la identidad ambiental en el envejecimiento puede ser definida como el sentido de conexión o conectividad que se establece entre los lugares o ambientes naturales, donde la persona adulta mayor desarrolla su vida cotidiana, a partir de relaciones emocionales, experiencias y de pertenencia del individuo a determinados entornos (Cuba y Hummon, 1993). También, la identidad ambiental en la vejez puede ser entendida como la interacción, exposición y percepción de los entornos naturales asociados al reconocimiento del lugar, donde se generan valores que contribuyen positivamente al estado de ánimo del adulto mayor y, de manera simbólica, a su identidad personal (Butz y Eyles, 1997, Stedman, 2002, Rowles, 2006, Tofle, 2009). Dicha identidad se genera a partir de una interacción simbiótica entre el entorno natural y las experiencias espaciales de la persona mayor, contribuyendo al desarrollo e integración de las comunidades que envejecen.

Algunos estudios indican que la exposición a paisajes naturales eleva la afectividad hacia el entorno cotidiano, por medio de comportamientos ecológicos, y se asocia positivamente con la salud física 
y psicológica (Park y Mattson, 2008, Gueguen y Stefan, 2014; Zhang et al. 2014). Asimismo el paisaje natural contribuye de forma terapéutica a su vida cotidiana, a través de favorecer su seguridad, identidad y conectividad con la naturaleza y comunidad. Al respecto, la frecuencia, proximidad y exposición a los paisajes naturales contribuyen al envejecimiento saludable, aumentando las estrategias proactivas frente a las presiones ambientales, proporcionando mayor percepción de seguridad y favoreciendo las actividades al aire libre, los encuentros sociales, y la empatía e identidad ambiental con los entornos naturales (Kaplan y Kaplan, 1996; Depledge et al. 2001; Mitchell y Phopham, 2007; Cervinka et al. 2012). Sin embargo, existe un limitado conocimiento de las repercusiones negativas que tiene la desaparición progresiva de los paisajes naturales sobre la identidad ambiental y el envejecimiento saludable, sobre todo, en las ciudades de América Latina.

En el año 2050 en la región se estima que uno de cada cuatro latinoamericanos será un adulto mayor y vivirá en las ciudades, sobre todo, en grandes áreas metropolitanas (Sánchez-González, 2007, Huenchuán, 2009). Sin embargo, el rápido crecimiento urbano no planificado está generando problemas medioambientales, como el aumento de la contaminación y la desaparición de áreas verdes (Melé, 2003), cuyos efectos sobre la población urbana de 60 y más años no han sido debidamente estudiados. Así, los parques naturales, de alto valor ecológico y simbólico para la comunidad, localizados en los límites de las grandes urbes, como Monterrey, se encuentran seriamente amenazados por el avance de la especulación urbanística, lo que puede tener efectos no deseados para las personas mayores del lugar.

El presente estudio, abordado desde el enfoque de la Gerontología Ambiental ${ }^{1}$ y la Geografía del Envejecimiento, analiza los factores del paisaje natural cotidiano que favorecen el envejecimiento saludable en el lugar y, en general, la calidad de vida de las personas mayores residentes en la colonia Olinalá del municipio de San Pedro Garza García, localizada en los límites del Parque Nacional Cumbres de la ciudad de Monterrey (México), cuyo entorno natural se encuentra amenazado por crecientes construcciones inmobiliarias. Uno de los aspectos reseñables del estudio es conocer la percepción de las personas mayores sobre su paisaje natural cotidiano, en el cual han convivido a lo largo de décadas, pero ahora se enfrenta a las incertidumbres de su deterioro.

En esta investigación se plantea la hipótesis de que el paisaje natural, como elemento simbólico, contribuye a la identidad ambiental, y, como elemento terapéutico, favorece el envejecimiento saludable en el lugar. De ello, se establece también que el deterioro del paisaje natural afecta negativamente tanto a la identidad ambiental como al envejecimiento saludable en el lugar. Así, se

1 Es una rama multidisciplinar de la Gerontología interesada en el análisis de las implicaciones socio-espaciales que se establecen entre los entornos físico-sociales y las personas mayores (Wahl y Weisman, 2003; Rodríguez-Rodríguez y Sánchez-González, 2016). 
propone la conservación de los paisajes naturales cotidianos para la promoción del envejecimiento saludable y, en general, la calidad de vida de las personas mayores, a través del acceso y contacto con la naturaleza, posibilitando la construcción de una sociedad más sostenible.

A través del estudio se trata de responder algunas interrogantes, como: qué elementos del paisaje natural se identifican las personas mayores; qué importancia tiene el paisaje natural cotidiano en el envejecimiento saludable en el lugar; cuáles son las principales amenazas del paisaje natural identificadas por los adultos mayores; cómo perciben las personas mayores la relación del deterioro ambiental y el aumento de los peligros naturales a nivel local con el cambio climático a nivel global; qué estrategias proponen los adultos mayores en materia de conservación y protección del paisaje natural.

\section{Metodología}

El estudio combina métodos cualitativos y cuantitativos con la finalidad de favorecer el conocimiento de los factores del paisaje natural cotidiano que condicionan tanto el envejecimiento saludable en el lugar, como la identidad ambiental de las personas mayores en los límites del Parque Natural Cumbres de Monterrey. Aquí, se han explorado la geografía de la vida cotidiana asociada a este lugar natural, así como las experiencias vividas por las personas mayores participantes. Desde una aproximación interdisciplinaria, se emplean técnicas etnográficas ${ }^{2}$ de fotovoz, ${ }^{3}$ mapas mentales ${ }^{4}$ y una encuesta personal no probabilística, además de sistemas de información geográfica (SIG). Así, en la elección de la muestra se siguieron los criterios de estudios similares (Andrews et al. 2009;

2 Los métodos etnográficos posibilitan un acercamiento a las memorias y experiencias vividas por las personas mayores, a través del empleo de imágenes y representaciones que favorecen la necesaria discusión (Harper, 2002; Crang, 2005; Degen y Rose, 2012).

3 La fotovoz es una técnica basada en la utilización de imágenes (fotografías, pinturas, videos o cualquier representación visual) en una entrevista, con objeto de facilitar los comentarios de los entrevistados. La finalidad de esta técnica no radica tanto en el estudio de las imágenes, como en el análisis de los significados personales, sociales y ambientales que los entrevistados les atribuyen (Ruby, 1995). Es decir, son el resultado de las emociones que despiertan las fotografías en el observador, cuya información genera ideas que no necesariamente se corresponden con los obtenidos en la investigación verbal (entrevista). En este trabajo las imágenes fueron proporcionadas por los propios entrevistados.

El empleo de mapas mentales posibilita una alternativa de delimitación de áreas urbanas y naturales que responde mejor a los intereses del usuario. En este sentido, la experiencia de las personas mayores puede contribuir a favorecer una cartografía de áreas de especial interés para la conservación de paisajes naturales, generando lazos con los entornos y desarrollando concepciones y acciones que están relacionadas a situaciones de apego al lugar, derivando en sentimientos de pertenencia y afecto entre la persona y el lugar, como también de familiaridad con el entorno (Burgess y Gold, 1982; Brown y Perkins, 1922; Gustafson, 2001; Pretty et al., 2003), convirtiéndose en una herramienta valiosa para la planificación, complementaria de los instrumentos de planificación técnica habituales.

4 El empleo de mapas mentales posibilita una alternativa de delimitación de áreas urbanas y naturales que responde mejor a los intereses del usuario. En este sentido, la experiencia de las personas mayores puede contribuir a favorecer una cartografía de áreas de especial interés para la conservación de paisajes naturales, generando lazos con los entornos y desarrollando concepciones y acciones que están relacionadas a situaciones de apego al lugar, derivando en sentimientos de pertenencia y afecto entre la persona y el lugar, como también de familiaridad con el entorno (Burgess y Gold, 1982; Brown y Perkins, 1922; Gustafson, 2001; Pretty et al. 2003), convirtiéndose en una herramienta valiosa para la planificación, complementaria de los instrumentos de planificación técnica habituales. 
Garvin et al., 2012), lo que posibilitó una muestra no probabilística compuesta de 16 personas de 60 y más años residentes en la zona de estudio, y cuya selección estuvo determinada por las siguientes características sociodemográficas: sexo, edad, nivel de estudios, forma de convivencia, lugar de nacimiento, años residiendo en la zona de estudio y percepción de la salud. También, uno de los principales problemas del trabajo de campo fue la alta inseguridad ciudadana, lo que condicionó la escasa participación de las personas mayores en el área de estudio. Por tal motivo, se optó por contactar a los adultos mayores a través de redes sociales y visitas a centros de estancia diurna e instituciones religiosas. Asimismo, en la muestra no participaron personas con discapacidad y dependencia, lo que condiciona en parte los resultados obtenidos, aunque no les resta interés.

Como primera estrategia metodológica, se realizó la encuesta personal no probabilística, cuyo diseño, previamente, había sido validado a partir de un pre-test. El cuestionario incorporó 20 preguntas relativas a las características sociodemográficas de las personas mayores, la percepción de su salud y su relación con el Parque Nacional Cumbres. Los resultados de la encuesta fueron analizados mediante pruebas estadísticas, como estadísticos descriptivos y la correlación Tau-b de Kendall.

En la segunda estrategia metodológica se empleó el método de fotovoz (Epstein, 2006; Ketelle, 2010; Garvin et al., 2012), con objeto de aproximarnos a las experiencias espacio-temporales de 16 personas mayores y evaluar los factores del paisaje natural cotidiano que determinan su identidad ambiental y condicionan su envejecimiento saludable (Tabla 1).

Tabla 1. Evaluación de los factores del paisaje natural cotidiano.

Resultados del método de fotovoz

\begin{tabular}{|l|c|c|c|c|}
\hline \multirow{2}{*}{$\begin{array}{l}\text { Factores del } \\
\text { paisaje natural } \\
\text { cotidiano }\end{array}$} & \multicolumn{4}{|c|}{ Identidad ambiental } \\
\cline { 2 - 5 } & $\begin{array}{c}\text { Muy Alto } \\
(++)\end{array}$ & $\begin{array}{c}\text { Alto } \\
(+-)\end{array}$ & $\begin{array}{c}\text { Medio } \\
(+)\end{array}$ & $\begin{array}{c}\text { Bajo } \\
(-)\end{array}$ \\
\hline Frecuencia de visitas & $\begin{array}{c}>3 \text { días } / \\
\text { semana }\end{array}$ & $\begin{array}{c}1-2 \text { días } / \\
\text { semana }\end{array}$ & $\begin{array}{c}1-2 \text { días } / \\
\text { semana }\end{array}$ & $<1$ día/ semana \\
\hline Proximidad al entorno & $\begin{array}{c}\text { Muy cerca } \\
(<800 \mathrm{~m})\end{array}$ & $\begin{array}{c}\text { Cerca } \\
(800-1600 \mathrm{~m})\end{array}$ & $\begin{array}{c}\text { Distante } \\
(1600-2400 \mathrm{~m})\end{array}$ & $\begin{array}{c}\text { Muy distante } \\
(>2400 \mathrm{~m})\end{array}$ \\
\hline $\begin{array}{l}\text { Presencia de memorias } \\
\text { y experiencias }\end{array}$ & Muy Alta & Alta & Media & $\begin{array}{c}\text { Baja y no hay } \\
\text { presencia }\end{array}$ \\
\hline Relaciones sociales & Muy altas & Altas & Moderadas & $\begin{array}{c}\text { Bajas y muy } \\
\text { bajas }\end{array}$ \\
\hline Ocio & Muy alto & Alto & Moderado & Bajo y muy bajo \\
\hline $\begin{array}{l}\text { Conservación de } \\
\text { vegetación autóctona }\end{array}$ & $\begin{array}{c}\text { Muy alta } \\
\text { (>80\%) }\end{array}$ & $\begin{array}{c}\text { Alta } \\
(60-80 \%)\end{array}$ & $\begin{array}{c}\text { Moderada } \\
\text { (40-60\%) }\end{array}$ & $\begin{array}{c}\text { Baja y muy baja } \\
\text { (<40\%) }\end{array}$ \\
\hline
\end{tabular}


Tabla 1. Continuación

\begin{tabular}{|l|c|c|c|c|}
\hline $\begin{array}{l}\text { Factores del paisaje } \\
\text { natural cotidiano }\end{array}$ & $\begin{array}{c}\text { Muy Alto } \\
(++)\end{array}$ & $\begin{array}{c}\text { Alto } \\
(+-)\end{array}$ & $\begin{array}{c}\text { Medio } \\
(+)\end{array}$ & $\begin{array}{c}\text { Bajo } \\
(-)\end{array}$ \\
\hline $\begin{array}{l}\text { Presencia de } \\
\text { construcciones }\end{array}$ & $\begin{array}{c}\text { Ninguna o } \\
\text { muy baja } \\
(<20 \%)\end{array}$ & $\begin{array}{c}\text { Baja } \\
(20-40 \%)\end{array}$ & $\begin{array}{c}\text { Moderada } \\
(40-60 \%)\end{array}$ & $\begin{array}{c}\text { Alta y muy alta } \\
(>60 \%)\end{array}$ \\
\hline $\begin{array}{l}\text { Presencia de } \\
\text { contaminación }\end{array}$ & $\begin{array}{c}\text { Muy baja } \\
(<20 \%)\end{array}$ & $\begin{array}{c}\text { Baja } \\
(20-40 \%)\end{array}$ & $\begin{array}{c}\text { Moderada } \\
(40-60 \%)\end{array}$ & $\begin{array}{c}\text { Alta y muy alta } \\
(>60 \%)\end{array}$ \\
\hline
\end{tabular}

Fuente: elaboración propia

Para ello, se entregaron cámaras fotográficas desechables a los adultos mayores participantes en el estudio, y que previamente habían recibido información sobre la investigación y proporcionado una guía con indicaciones. Así, en la Figura 1 se muestra el esquema general empleado por las personas mayores participantes a través del método de fotovoz.

Figura 1. Esquema general para el desarrollo del método de fotovoz por las personas mayores. Colonia Olinalá y Parque Nacional Cumbres, Monterrey, 2014

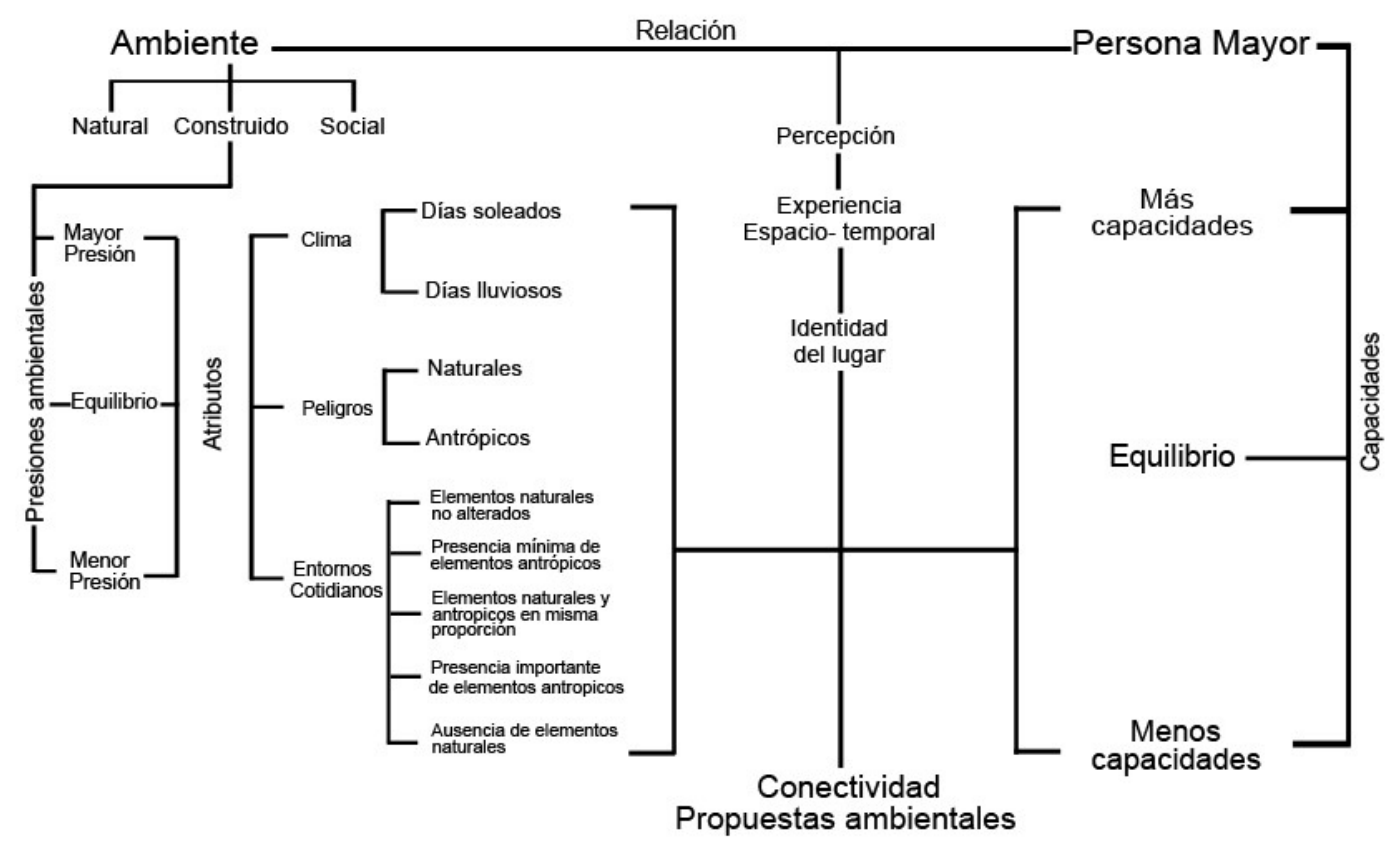

Fuente: elaboración propia

Asimismo, durante abril de 2014 cada persona mayor participante realizó 10 fotografías de su paisaje natural cotidiano que, posteriormente, fueron comentadas en dos grupos de discusión formados por los participantes del estudio, con la finalidad de provocar recuerdos, comentarios y 
discusiones (Harper, 2002; Garvin et al., 2012). Además, se calcularon frecuencias y porcentajes de los datos obtenidos de los elementos predominantes en las 160 imágenes fotográficas.

En la tercera estrategia metodológica se empleó la técnica de los mapas mentales con objeto de percibir la imagen del paisaje natural cotidiano de los adultos mayores e identificar en una representación gráfica los elementos principales del área de estudio (bordes, hitos, senderos, nodos y áreas) (Lynch, 1960). Para ello, se solicitó a los 16 participantes que elaboraran mapas mentales del área de estudio, a través de dibujos sobre papel, en los que se representasen los elementos significativos de su paisaje natural cotidiano. Además, en el trabajo de campo se realizaron visitas periódicas al área de estudio con objeto de localizar los diferentes bordes, hitos, senderos, nodos y áreas identificados por las personas mayores.

Como cuarta estrategia metodológica se emplearon Sistemas de Información Geográfica, a través del software ArcGIS, para elaborar mapas temáticos con la información obtenida de los métodos de fotovoz y de mapas mentales, constituyendo una valiosa herramienta de análisis y consulta para la planificación urbana gerontológica y la protección de los paisajes naturales que potencian el envejecimiento saludable en el lugar.

\section{3 Área de estudio}

En la periferia del área metropolitana de Monterrey (México) se localiza el área de estudio, la colonia Olinalá del municipio de San Pedro Garza García, dominada por un clima subtropical y ubicada en un terreno accidentado del sistema montañoso de Sierra Madre Oriental y en los límites del Parque Nacional Cumbres. Aunque está declarado área natural protegida (CONANP, 2006), el parque se encuentra amenazado por el crecimiento urbano y la contaminación atmosférica. ${ }^{5}$ Como consecuencia, se ha afectado el hábitat natural de bosques de encinos y pinos y la fauna silvestre, con endemismos y especies en peligro como el oso negro. Además, en el área de estudio se ha observado el incremento de los peligros naturales, como inundaciones recurrentes por ciclones tropicales y procesos de remoción en masa asociados a la pérdida de suelo por erosión y, en general, a los efectos del cambio climático (Chávez y Sánchez-González, 2016).

Entre los años 2000 y 2010 en la colonia Olinalá se ha producido un importante crecimiento urbanístico, sobre todo en terrenos del parque natural (Figura 2), que ha triplicado el número de viviendas, de 91 a 375 viviendas, mientras que en el municipio de San Pedro Garza García el incremento inmobiliario ha sido significativamente menor (26.6\%). Según los datos censales, las viviendas cuentan con todos los servicios y el valor de los inmuebles es alto, según las agencias inmobiliarias. El $86.4 \%$ de las viviendas están habitadas y un $13.6 \%$ son segundas residencias. En

5 Monterrey es la segunda ciudad de América Latina y el Caribe con los mayores niveles de contaminación atmosférica (OMS, 2016). 
el mismo periodo la población total de la colonia se ha duplicado, pasando de 572 a 1178 personas, aunque a un ritmo de crecimiento inferior al experimentado por sector inmobiliario en Monterrey. Por su parte, el municipio ha experimentado un crecimiento demográfico negativo del $2.7 \%$, de 125978 a 122659 habitantes. Asimismo, la población de 60 y más años en la colonia ha aumentado de 14 a 116 personas, mientras que su peso relativo se ha incrementado del $2.4 \%$ al 9.8\% del total, un porcentaje algo inferior a la media municipal (12.5\%), aunque superior a media del área metropolitana de Monterrey (8.4\%), y la media nacional (9\%) (INEGI, 2010).

Figura 2. Localización del área de estudio y presencia de viviendas en el Parque Nacional Cumbres. Colonia Olinalá, Monterrey, 2014

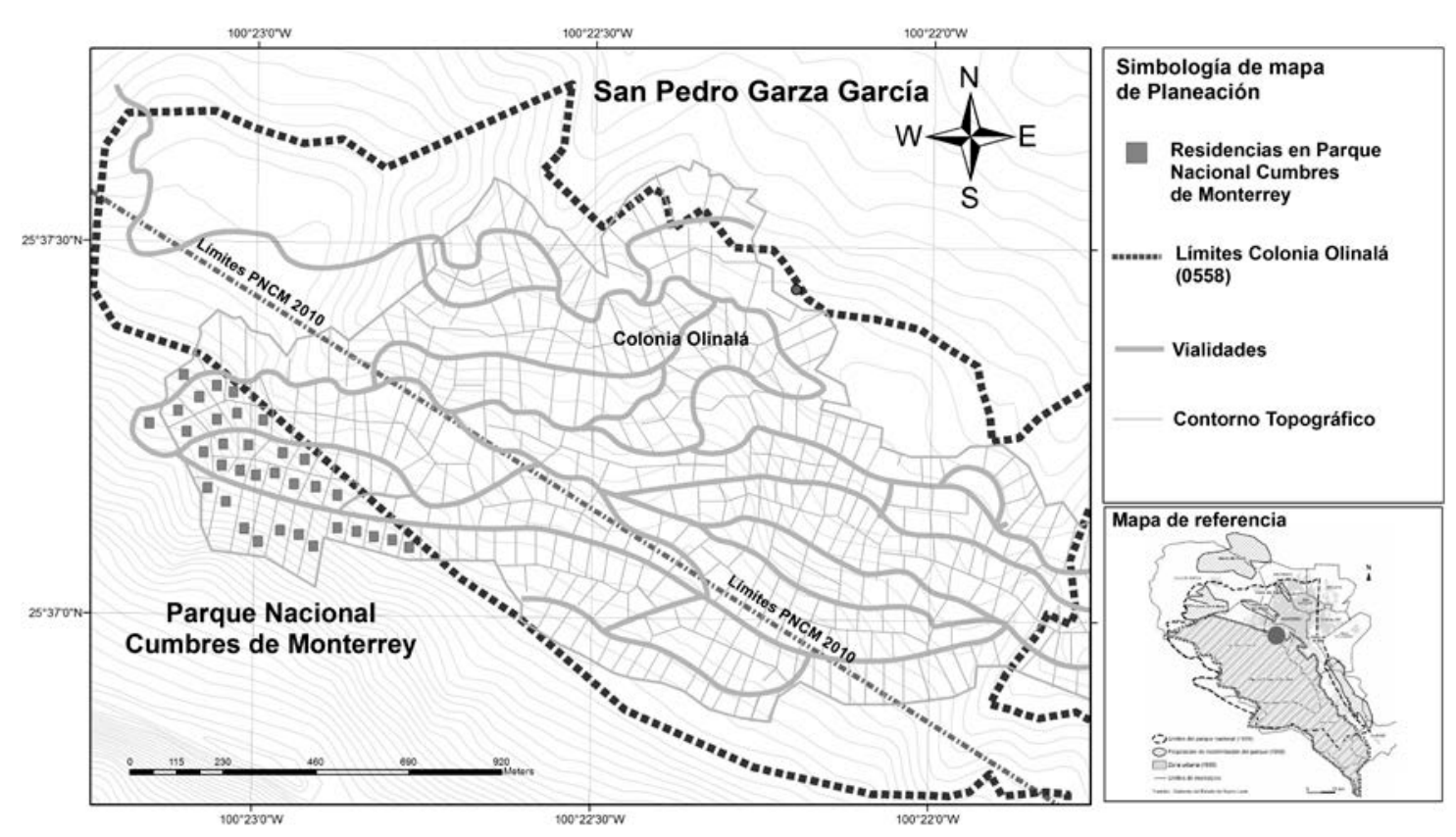

Leyenda: Los límites de la colonia Olinalá ajustados al AGEB 0558, es una área geoestadística básica usada por el Instituto Nacional de Estadística y Geografía (INEGI) a escala intramunicipal.

Fuente: elaboración propia a partir de los trabajos de Melé (2003),

CONANP (2006), INEGI (2010) y el trabajo de campo

También, en la zona de estudio se observan diferencias según género y edad en el grupo de personas mayores, con más varones (63.8\%) que mujeres (36.2\%), y con más personas menores de 70 años (77.6\%) que mayores (22.4\%). Asimismo, los datos del censo del 2010 indican que la población de 60 y más años presenta un nivel socioeconómico medio y alto, lo que coincide con los resultados obtenidos en la selección de la muestra.

\section{Resultados}

La muestra definitiva estuvo compuesta por 16 personas de 60 y más años del área de estudio, con un predominio de mujeres (56.3\%) sobre varones (43.8\%), así como que cuatro de cada cinco 
adultos mayores tenía menos de 75 años, y solo un 18.8 \% habían cumplido los 75 y más años (Tabla 2). También, el $62.5 \%$ convivía con su cónyuge, mientras que el $18.8 \%$ vivía solo. Asimismo, es reseñable que el 68.8 \% hubiera nacido en la misma entidad y que el 87,5\% residía en la zona desde hacía 25 y más años. Por su parte, la mayoría de los participantes contaban con estudios universitarios (87.5\%), frente a un $6.3 \%$ que habían terminado estudios primarios. Igualmente, tres de cada cuatro personas mayores vivían en un domicilio próximo al parque natural (menos de 1600 metros) y, de éstos, el $62.5 \%$ lo frecuentaba uno y más días a la semana. A la inversa, el $6.3 \%$ de los adultos mayores vivía a una distancia superior a 2400 metros del parque natural y, de los cuales, el $18.8 \%$ lo frecuentaba menos de 1 día al mes. Así, el $62.5 \%$ admitía tener una alta y muy alta frecuencia de relaciones sociales en contraste con el $6.3 \%$ que señalaba tener una baja y muy baja frecuencia. Por su parte, el $56.6 \%$ practicaba con mucha o muchísima frecuencia alguna actividad de ocio, frente al $18.8 \%$ que practica ocio con poca o muy poca frecuencia.

En lo que respecta a la salud auto percibida, el $81.3 \%$ de las personas mayores la percibía como buena y muy buena, frente al 6.3 \% que señalaba una mala y muy mala salud (Tabla 2). Lo anterior estaría relacionado con que el $68.8 \%$ no presentaba problemas de movilidad y que el $62.5 \%$ no necesitaba ayuda en las actividades de la vida diaria. Precisamente, se observan asociaciones significativas entre la percepción de la salud y la necesidad de ayuda (0.701) y edad (-0.577), lo que refleja que a medida que se envejece disminuyen las capacidades y la percepción positiva de la salud, así como aumentan las necesidades de ayuda (Compán y Sánchez-González, 2005). Precisamente, el nivel de estudios se confirmó como la variable más predictiva en relación a la percepción de la salud (0.812) y la edad (-0.533). Así, los años de estudio condicionan la vida laboral, el nivel socioeconómico (pensiones), y, en cierta medida, las patologías en la vejez, sobre todo de las mujeres de 75 y más años, que tuvieron más dificultades de acceso a la educación (Sánchez-González y Egea, 2011). Del mismo modo, la percepción de la salud se asoció significativamente con las variables proximidad al parque (0.653), frecuencia de visitas al parque (0.632), presencia de recuerdos y vivencias del parque $(0.576)$, frecuencia de práctica de ocio $(0.566)$ y frecuencia de relaciones sociales $(0.555)$, lo que subraya la importancia del paisaje natural y las áreas verdes en el fomento de las actividades cotidianas (relaciones sociales y ocio) y, en general, en el envejecimiento saludable en el lugar. 
Tabla 2. Relación entre características sociodemográficas, percepción de salud, conservación de la vegetación y presencia de memorias y experiencias en el parque.

Monterrey, 2014 (\% y coeficiente de correlación Tau B de Kendall)

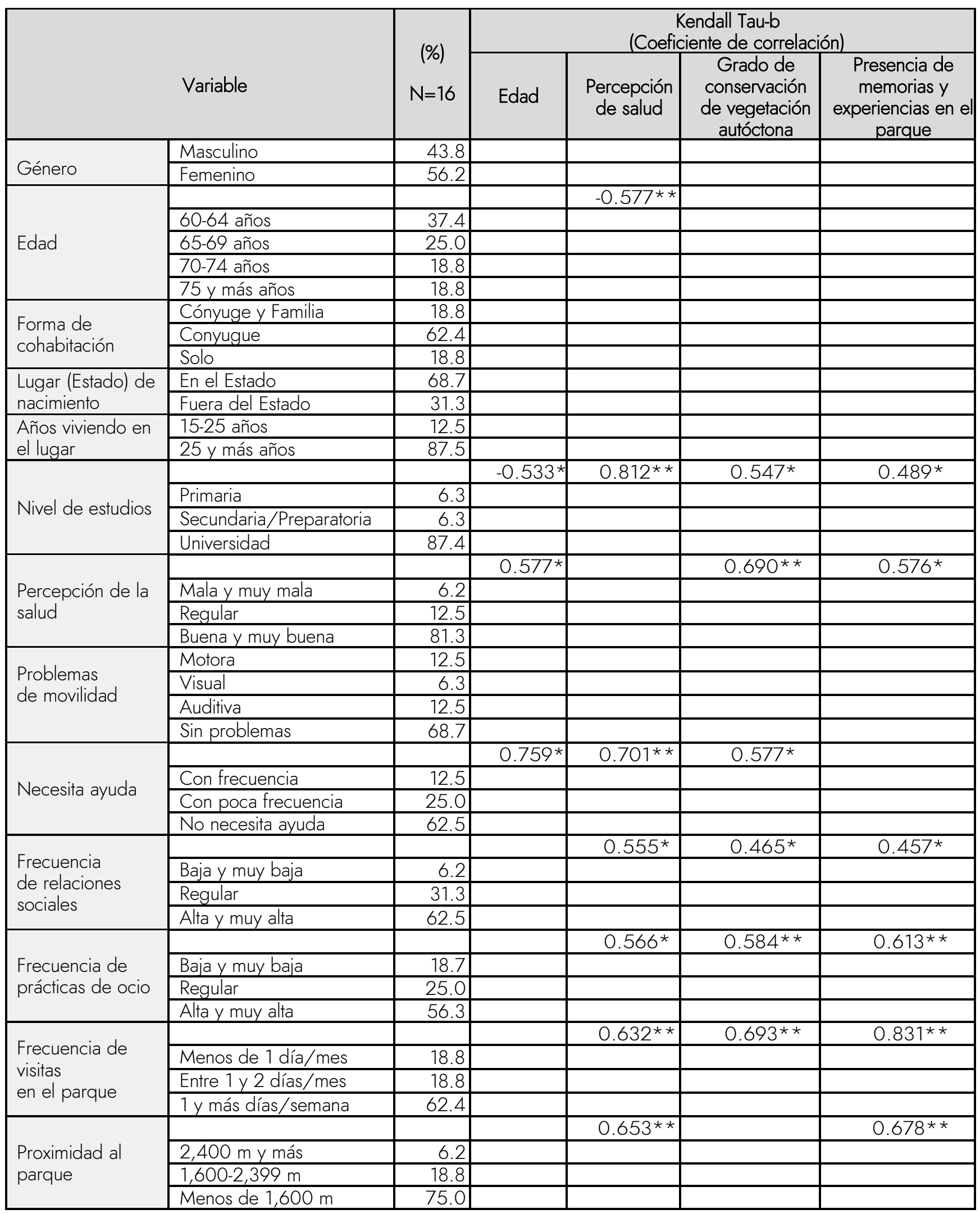


Tabla 2. Continuación

\begin{tabular}{|c|c|c|c|c|c|c|}
\hline \multirow{2}{*}{\multicolumn{2}{|c|}{ Variable }} & \multirow{3}{*}{$\begin{array}{c}(\%) \\
N=16\end{array}$} & \multicolumn{4}{|c|}{$\begin{array}{c}\text { Kendall Tau-b } \\
\text { (Coeficiente de correlación) }\end{array}$} \\
\hline & & & \multirow{2}{*}{ Edad } & \multirow{2}{*}{$\begin{array}{r}\begin{array}{r}\text { Percepción } \\
\text { de salud }\end{array} \\
0.576^{\star}\end{array}$} & \multirow{2}{*}{$\begin{array}{c}\begin{array}{c}\text { Grado de } \\
\text { conservación } \\
\text { de vegetación } \\
\text { autóctona }\end{array} \\
0.716^{\star \star}\end{array}$} & \multirow{2}{*}{$\begin{array}{l}\text { Presencia de } \\
\text { memorias y } \\
\text { experiencias en } \\
\text { el parque } \\
\end{array}$} \\
\hline \multirow{5}{*}{$\begin{array}{l}\text { Presencia de } \\
\text { memorias y } \\
\text { experiencias en el } \\
\text { parque }\end{array}$} & & & & & & \\
\hline & Ninguna memoria & 6.1 & & & & \\
\hline & Pocas memorias & 31.3 & & & & \\
\hline & $\begin{array}{l}\text { Presencia moderada de } \\
\text { memorias }\end{array}$ & 31.3 & & & & \\
\hline & Muchas memorias & 31.3 & & & & \\
\hline \multirow{4}{*}{$\begin{array}{l}\text { Percepción del grado } \\
\text { de conservación de } \\
\text { vegetación } \\
\text { autóctona }\end{array}$} & & & & $0.690 *$ & & $0.716^{\star \star *}$ \\
\hline & Mala y muy mala & 18.8 & & & & \\
\hline & Regular & 18.8 & & & & \\
\hline & Buena y muy buena & 62.4 & & & & \\
\hline \multirow{4}{*}{$\begin{array}{l}\text { Percepción de } \\
\text { presencia de } \\
\text { construcciones } \\
\text { (viviendas) en el } \\
\text { parque natural } \\
\end{array}$} & & & & $0.613^{*}$ & $0.766 * *$ & $0.656 * \star$ \\
\hline & Alto y muy alto & 25.0 & & & & \\
\hline & Regular & 37.5 & & & & \\
\hline & Bajo y muy bajo & 37.5 & & & & \\
\hline \multirow{4}{*}{$\begin{array}{l}\text { Percepción de grado } \\
\text { de contaminación } \\
\text { (desechos urbanos) } \\
\text { en el parque natural }\end{array}$} & & & & $0.508 *$ & $0.798 * \star$ & $0.595 * *$ \\
\hline & Alto y muy alto & 37.4 & & & & \\
\hline & Regular & 31.3 & & & & \\
\hline & Bajo y muy bajo & 31.3 & & & & \\
\hline \multirow{4}{*}{$\begin{array}{l}\text { Percepción de } \\
\text { protección del medio } \\
\text { ambiente }\end{array}$} & & & & & $0.585^{\star}$ & $0.626 * *$ \\
\hline & Bajo y muy bajo & 62.5 & & & & \\
\hline & Regular & 37.5 & & & & \\
\hline & Alto y muy alto & 0.0 & & & & \\
\hline \multirow{4}{*}{$\begin{array}{l}\text { Percepción de } \\
\text { peligros naturales }\end{array}$} & & & & & $0.594^{*}$ & \\
\hline & Alto y muy alto & 18.7 & & & & \\
\hline & Regular & 68.8 & & & & \\
\hline & Bajo y muy bajo & 12.5 & & & & \\
\hline \multirow{3}{*}{$\begin{array}{l}\text { Participación en } \\
\text { actividades de } \\
\text { cuidado ambiental }\end{array}$} & $\begin{array}{l}\text { Baja y muy baja } \\
\text { participación }\end{array}$ & 31.1 & & & & \\
\hline & Participación moderada & 43.8 & & & & \\
\hline & $\begin{array}{l}\text { Alta y muy alta } \\
\text { participación }\end{array}$ & 25.1 & & & & \\
\hline
\end{tabular}

Leyenda: ${ }^{* *}$ ) Correlación significativa en el nivel 0.01 (bilateral)

(*) Correlación significativa en el nivel 0.05 (bilateral)

Fuente: elaboración propia

La conservación de la vegetación autóctona se mostró como un buen indicador de la salud percibida (0.690) y, en general, de la relación cotidiana de la persona mayor con el parque natural (Tabla 2). Al respecto, el $62.6 \%$ tenía una buena y muy buena percepción del grado de conservación de la vegetación, mientras que el 18.8 \% percibe la conservación de la misma como mala y muy mala. Así, las causas del deterioro progresivo de la vegetación autóctona del parque natural se asocian con la contaminación de residuos sólidos urbanos (0.798) y la presencia de construcciones (0.766), así como a la percepción de los peligros naturales (0.594) y la percepción de la seguridad (0.585). También, el grado de conservación de la vegetación autóctona se asocia 
con la frecuencia de visitas al parque (0.632). De ello, se deduce la importancia de la conservación de la vegetación autóctona del parque natural por las implicaciones positivas en potenciar estilos de vida saludables entre las personas mayores.

La presencia de recuerdos y vivencias del parque es un buen indicador de la importancia del paisaje natural como elemento simbólico que contribuye a la identidad ambiental de las personas mayores. Así, observamos una asociación significativa entre la presencia de recuerdos y vivencias del parque y la frecuencia de visitas al mismo (0.831), el grado de conservación de la vegetación autóctona (0.716), y su proximidad (0.678) (Tabla 4). En la misma, se deduce la importancia de contacto cotidiano de las personas mayores con el paisaje natural del parque, ya que refuerza la presencia de recuerdos y vivencias, y con ello, la práctica de ocio (0.613), la percepción de la salud (0.576) y las relaciones sociales (0.457). También, se indica que la presencia de recuerdos del parque se relaciona de forma negativa con la presencia de construcciones en el parque (0.656), la percepción de seguridad (0.626), y el grado de contaminación (0.595). Del mismo modo, se observó que uno de cada cuatro adultos mayores tenía una alta o muy alta predisposición a participar en actividades de cuidado ambiental, lo que refleja la preferencia de este colectivo a colaborar en actividades de conservación ambiental.

De los resultados de la encuesta se desprende que la población encuestada disfruta de un cierto nivel socioeconómico, buena salud y relaciones sociales, así como informa de una amplia experiencia de vivir en el lugar, lo que es determinante en la comprensión de la identidad ambiental en el proceso de envejecer en el lugar. De este modo, se deduce la necesidad de preservar la vegetación autóctona y, en general, el paisaje del parque natural, ante los peligros del crecimiento urbano, con la finalidad de potenciar los vínculos emocionales y los estilos de vida saludables de las personas mayores. Además, se subraya la importancia del paisaje natural como elemento simbólico que contribuye a la identidad ambiental, y como elemento terapéutico que favorece el envejecimiento saludable en el lugar.

Las 160 imágenes fotográficas realizadas por los adultos mayores participantes y utilizadas por el método de fotovoz se realizaron, principalmente, en días soleados (65.6\%), y captan, predominantemente, elementos de la naturaleza vinculados al paisaje cotidiano, como árboles (32.4\%), flores $(20.5 \%)$ y arroyos $(15.7 \%)$, así como personas (27.5\%) y mobiliario urbano (4.9\%) (Tabla 3 y Figuras 3-12). 
Tabla 3. Principales elementos y peligros del paisaje natural cotidiano en el Parque Nacional Cumbres. Colonia de Olinalá, Monterrey, 2014

\begin{tabular}{|l|c|c|c|c|c|c|}
\hline \multirow{2}{*}{ Dimensiones } & \multicolumn{2}{|c|}{ Total } & \multicolumn{2}{c|}{$\begin{array}{c}\text { Imágenes días } \\
\text { soleados }\end{array}$} & \multicolumn{2}{c|}{$\begin{array}{c}\text { Imágenes días } \\
\text { lluviosos }\end{array}$} \\
\cline { 2 - 8 } & $(\mathrm{N})$ & $\begin{array}{c}(\% \\
\text { columna) }\end{array}$ & $(\mathrm{N})$ & $(\%$ fila) & $(\mathrm{N})$ & (\% fila) \\
\hline $\begin{array}{l}\text { Elementos principales del paisaje natural cotidiano } \\
\text { con el cual se identifican }\end{array}$ & 102 & 100.0 & 75 & 73.5 & 27 & 26.5 \\
\hline Árboles & 33 & 32.4 & 27 & 81.8 & 6 & 18.2 \\
\hline Flores & 21 & 20.6 & 19 & 90.5 & 2 & 9.5 \\
\hline Ríos & 16 & 15.7 & 8 & 50.0 & 8 & 50.0 \\
\hline Personas (relaciones sociales) & 27 & 26.5 & 17 & 63.0 & 10 & 37.0 \\
\hline Mobiliario urbano & 5 & 4.9 & 4 & 80.0 & 1 & 20.0 \\
\hline Principales peligros del paisaje natural cotidiano & 58 & 100.0 & 30 & 51.7 & 28 & 48.3 \\
\hline Construcciones en el interior del parque natural & 18 & 31.0 & 14 & 77.8 & 4 & 22.2 \\
\hline Peligros naturales (inundaciones y deslaves) & 20 & 34.5 & 2 & 10.0 & 18 & 90.0 \\
\hline Vandalismo e inseguridad & 12 & 20.7 & 10 & 83.3 & 2 & 16.7 \\
\hline Falta de limpieza & 8 & 13.8 & 4 & 50.0 & 4 & 50.0 \\
\hline Total & 160 & 100.0 & 105 & 65.6 & & \\
\hline
\end{tabular}

Nota: La información obtenida de la interpretación de las imágenes en los grupos de discusión.

Fuente: elaboración propia

Figuras 3-12. Método de fotovoz. Fotografías y comentarios de las personas mayores participantes

Figura 3. Entorno natural. Parque Nacional Cumbres

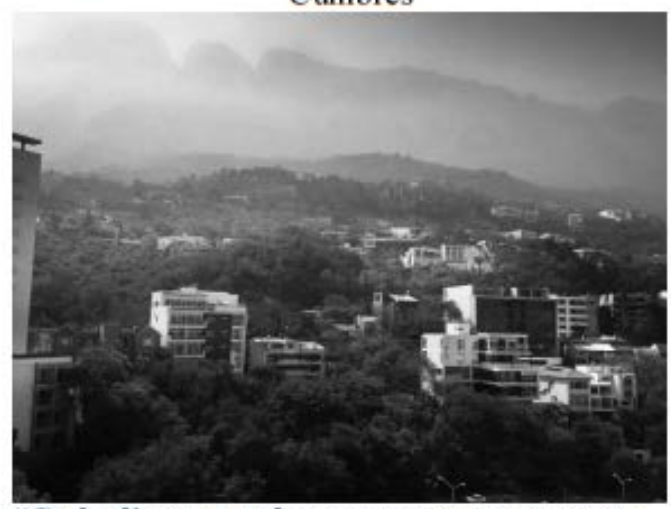

"Cada dia que me levanto con este paisaje es gratificante, la verdad cuando me llevan a la ciudad me estreso, prefiero quedarme aqui aunque llueva y sea dificil moverse". F, 64 .
Figura 4. Árbol: Elemento principal del entorno natural.

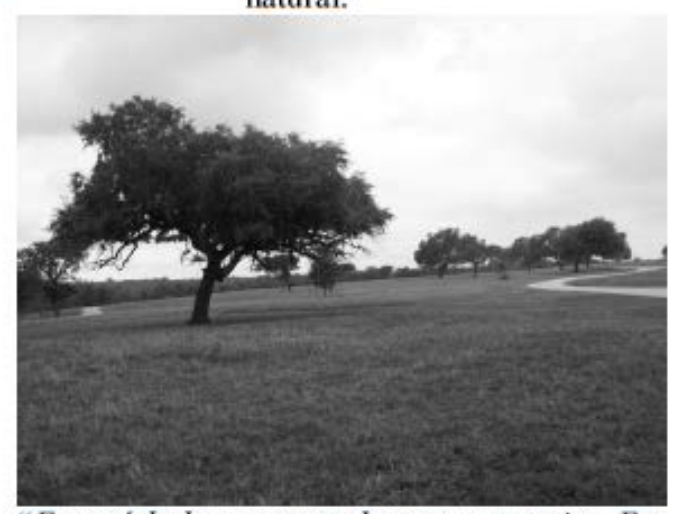

"Estos árboles me traen buenas memorias. Ese árbol, nosotros lo cuidamos y creció. Siempre que venimos a visitarlo era nuestro lugar de encuentro. Estábamos sentados bajo su sombra para comer en familia y aqui continua cuidado y derecho." $M, 74$. 
Figura 5. Relación entre personas mayores y el entorno natural

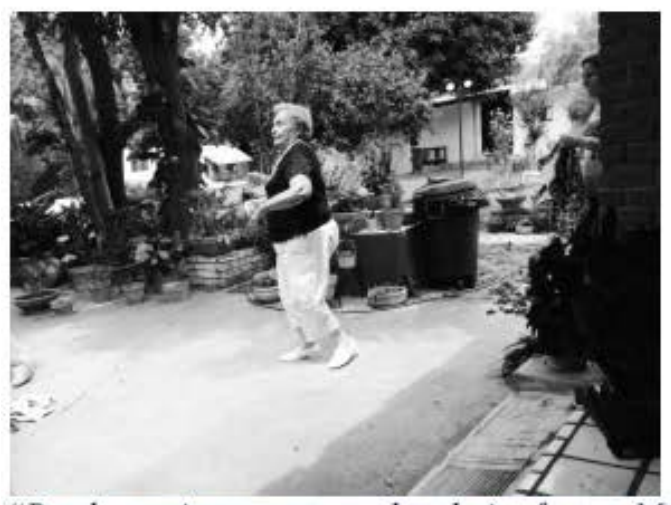

"Puedo caminar un poco, oler el aire fresco. Me gusta venir a los campos, donde todavia hay lugares que recuerdo de la ciudad. Tengo problemas para caminar, pero esto me hace sentir feliz". $F, 90$.

Figura 7. Persona mayor en un parque público

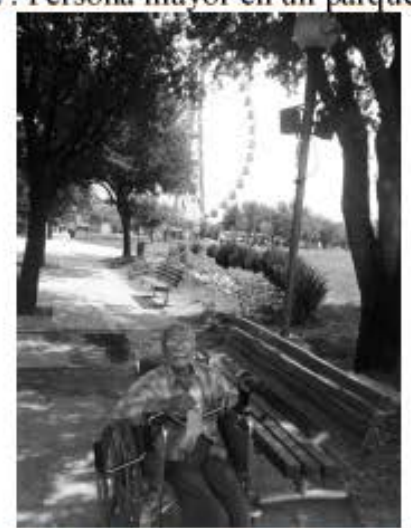

"Aqui puedo ir de un lado a otro y me siento como en casa, aqui afuera es mu grande, no puedo caminarlo, pero hay aire limpio". M, 95 .

Figura 9. Día lluvioso. Percepción de los peligros naturales de inundaciones y deslaves

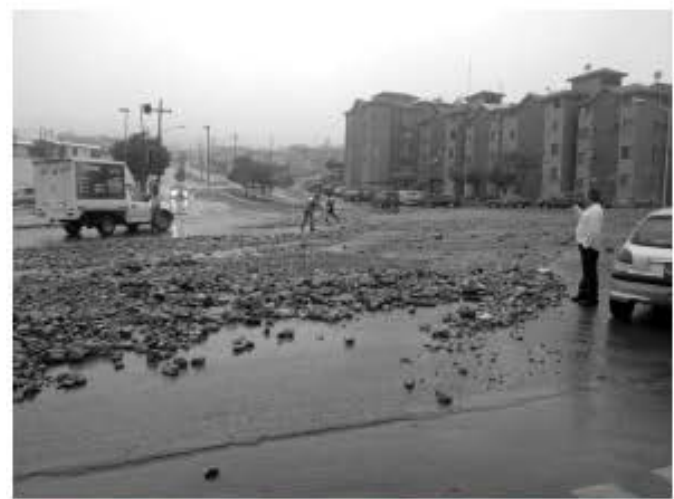

"Vivimos rodeados de montañas y esto ha sido siempre y ya que cada vez somos más personas. Veo que con el paso del tiempo, han empeorado las imundaciones y deslaves en ellos". $M, 70$.
Figura 6. Jardines privados y flores como elementos importantes del entorno natural, identificados por los adultos mayores

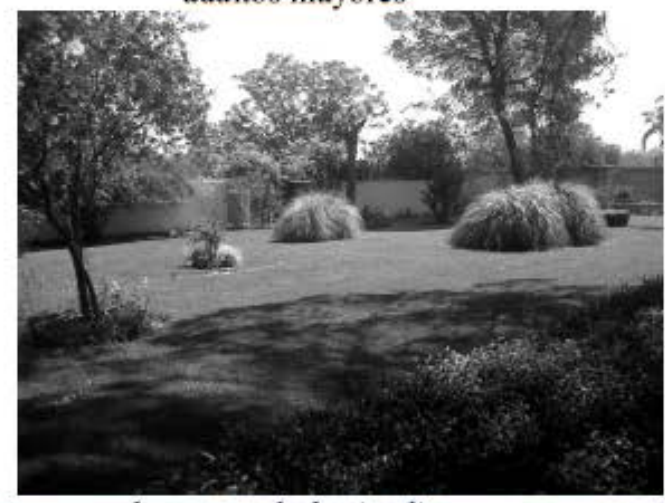

"Siempre me han gustado los jardines; es un escape para mi. Mi infancia fue complicada, por lo que tener un lugar lleno de plantas, me hace sentirme orgulloso y complete". F, 70 .

Figura 8. Construcciones ilegales y destrucción del entorno natural

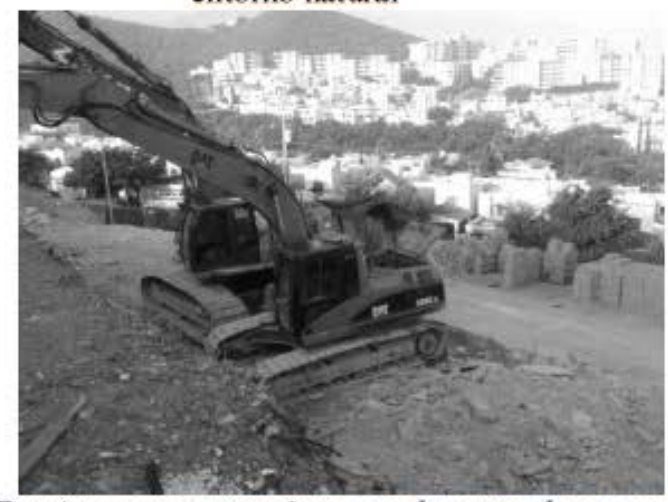

"Es triste ver que terminan con la naturaleza, con razón hay más contaminación en Monterrey. Qué lástima que no importa para los desarrolladores el cuidar de la naturaleza." $M, 65$.

Figura 10. Acceso al Parque en día lluvioso.

Peligros naturales por desprendimientos

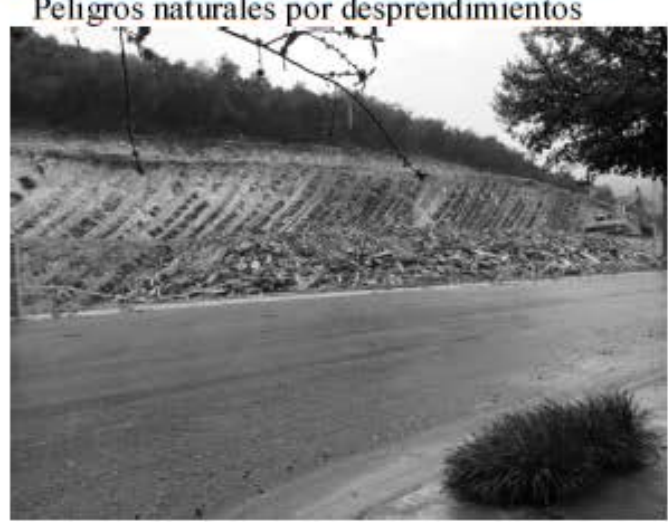

"Tengo miedo que las rocas pueden caerte encima o quedar atrapados por un deslave, aun asi este camino es lindo para caminarlo. Siempre me da más seguridad cuando está soleado". F, 62. 
Figura 11. Mobiliario urbano destruido. Problema de vandalismo y de seguridad

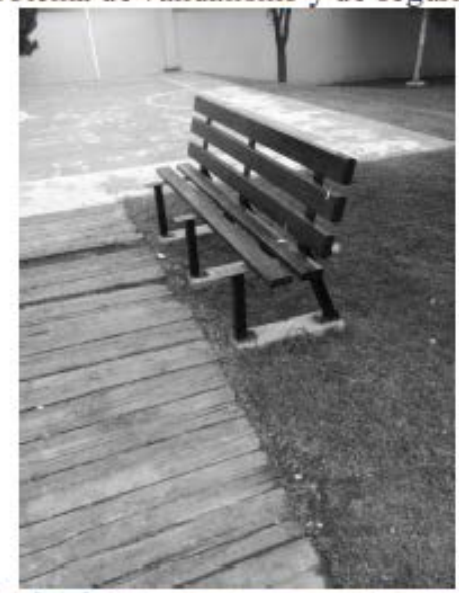

"Esto fue hecho por unos niños que van mucho al parque. Nos gusta visitar el parque sólo cuando está en calma, pero hay veces que ni siquiera tenemos donde sentarnos. Eso de quemar cosas, no me dan ganas de ir al parque. " $F, 66$.
Figura 12. Participación comunitaria

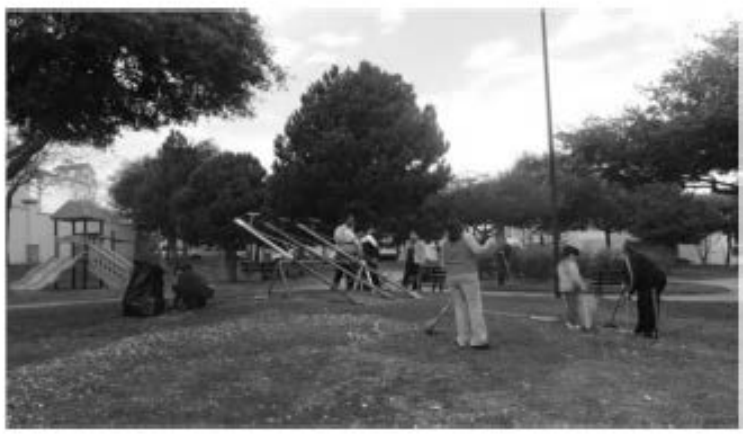

"En la colonia el comité de vecinos realizaron actividades de dispersión social, invitando a tomar parte las personas mayores, me he incluido. Lo que hicimos fue hacer actividades para enseñar a los niños a cuidar de las plantas sembrarlas, como un taller, creo que algo podemos empezar", F, 62 .

Fuente: elaboración propia

La discusión de las imágenes comentadas por las personas mayores en relación al grado de conservación del paisaje natural y la construcción de su identidad ambiental ha permitido elaborar la Tabla 4. Así, la perspectiva temporal estuvo presente en el $18.7 \%$ de las imágenes, que vincularon a vivencias actuales (60\%) y recuerdos pasados (40\%). Del mismo modo, con respecto a la frecuencia de visitas al parque, predominan las imágenes de lugares que visitan de forma cotidiana (84.6\%), frente aquellos lugares que visitan en menor medida (15.4\%). Lo anterior se explicaría en base a que la mayoría de las imágenes se asocian con paisajes próximos al domicilio (87.5 \%). También, se indica que las imágenes se localizan, sobre todo, en entornos ubicados en los límites del parque nacional (84.2\%). Además, las imágenes alusivas a los peligros naturales permitieron a los adultos mayores vincularlos con los efectos del cambio climático a nivel global (92.6\%), de lo cual se desprende una alta concienciación sobre la cuestión, desmintiendo la idea de la desvinculación de este colectivo sobre los retos climáticos para las futuras generaciones.

La discusión de las imágenes hacían alusión a la importancia de las propuestas ambientales en la conservación del parque, como la participación comunitaria (71.4\%), donde algunos colaboran activamente, y la educación y concienciación de las nuevas generaciones (28.6\%). Aquí, la participación comunitaria de los adultos mayores (Figura 13), como agentes de cambio, favorece su integración y relaciones sociales, así como genera un sentimiento de utilidad que ayuda a potenciar sus capacidades (Lawton, 1999; Tabbarah et al., 2000).

Los resultados del análisis de las imágenes por fotovoz indican que la percepción de los elementos del entorno natural está asociada con las relaciones emocionales, experiencias y de pertenencia al 
lugar del individuo, así como sus estados de ánimo (Lalli, 1992; Cuba y Hummon, 1993; Stedman, 2002; Tofle, 2009). Igualmente, los participantes reaccionaron de diferente forma ante los mismos ambientes, lo que está determinado por su experiencia y apego al entorno natural (Rodhe y Kendle, 1994). También, las personas mayores se identifican con los elementos de la naturaleza vinculados al paisaje del parque natural, así como la presencia de personas en el espacio público se relaciona con la importancia de las relaciones sociales en el envejecimiento. Asimismo, los adultos mayores indicaron que se generan sentimientos de pertenencia hacia estos entornos naturales, los cuales, favorecen sensaciones de seguridad y confort (Gustafson, 2001; Brown y Perkins, 1997; Butz y Eyles, 1997; Chawla, 1992). Del mismo modo, se observan que las amenazas de las construcciones en el parque y los peligros naturales, como inundaciones y deslaves, pueden afectar negativamente el paisaje natural y, con ello, la construcción de la identidad ambiental. Así, deducimos que el deterioro del paisaje natural puede implicar un cambio en la manera de percibir el entorno y su seguridad, así como puede repercutir negativamente en el envejecimiento saludable en el lugar.

Tabla 4. Evaluación del grado de conservación de los paisajes naturales cotidianos del Parque Nacional Cumbres. Colonia Olinalá, Monterrey, 2014

\begin{tabular}{|c|c|c|c|c|c|c|c|}
\hline & \multicolumn{7}{|c|}{ Grado de conservación de los elementos del paisaje natural cotidiano } \\
\hline & \multicolumn{2}{|c|}{$\begin{array}{l}\text { Total } \\
\mathrm{N} \\
\text { (\% por } \\
\text { columna) }\end{array}$} & \multirow{2}{*}{$\begin{array}{c}\text { Elementos } \\
\text { naturales } \\
\text { no } \\
\text { alterados } \\
\text { (\% por } \\
\text { filas) } \\
0,0\end{array}$} & \multirow{2}{*}{$\begin{array}{l}\text { Presencia } \\
\text { mínima de } \\
\text { elementos } \\
\text { antrópicos } \\
\text { (\% por } \\
\text { filas) } \\
6,7\end{array}$} & \multirow{2}{*}{$\begin{array}{l}\text { Elementos } \\
\text { naturales y } \\
\text { antrópicos } \\
\text { en misma } \\
\text { proporción } \\
\text { (\% por } \\
\text { filas) } \\
20,0\end{array}$} & \multirow{2}{*}{$\begin{array}{c}\text { Presencia } \\
\text { importante } \\
\text { de } \\
\text { elementos } \\
\text { antrópicos } \\
\text { (\% por } \\
\text { filas) } \\
26,7\end{array}$} & \multirow{2}{*}{$\begin{array}{c}\begin{array}{c}\text { Ausencia } \\
\text { elementos } \\
\text { naturales } \\
\text { (\% por } \\
\text { filas) }\end{array} \\
46,7\end{array}$} \\
\hline Desde la perspectiva temporal & 30 & 100.0 & & & & & \\
\hline Paisaje relacionado con recuerdos pasados & 12 & 40.0 & 0,0 & 0,0 & 25,0 & 41,7 & 33,3 \\
\hline $\begin{array}{l}\text { Paisaje relacionado con experiencias o } \\
\text { vivencias actuales }\end{array}$ & 18 & 60.0 & 0,0 & 11,1 & 16,7 & 16,7 & 55,6 \\
\hline $\begin{array}{l}\text { Desde la perspectiva de la frecuencia de } \\
\text { asistencia al lugar }\end{array}$ & 13 & 100.0 & 15,4 & 7,7 & 15,4 & 30,8 & 30,8 \\
\hline $\begin{array}{l}\text { Paisaje que visita de forma cotidiana o } \\
\text { frecuente }\end{array}$ & 11 & 84.6 & 0,0 & 9,1 & 18,2 & 36,4 & 36,4 \\
\hline Paisaje que visita de forma poco frecuente & 2 & 15.4 & 100,0 & 0,0 & 0,0 & 0,0 & 0,0 \\
\hline Desde la perspectiva de la localización & 19 & 100.0 & 0,0 & 5,3 & 26,3 & 42,1 & 26,3 \\
\hline Paisaje dentro del Parque Nacional Cumbres & 3 & 15.8 & 0,0 & 33,3 & 66,7 & 0,0 & 0,0 \\
\hline Paisaje fuera del Parque Nacional Cumbres & 16 & 84.2 & 0,0 & 0,0 & 18,8 & 50,0 & 31,3 \\
\hline $\begin{array}{l}\text { Desde la perspectiva de la proximidad al } \\
\text { domicilio }\end{array}$ & 16 & 100.0 & 0,0 & 6,3 & 31,3 & 25,0 & 37,5 \\
\hline Paisaje próximo a la vivienda & 14 & 87.5 & 0,0 & 0,0 & 28,6 & 28,6 & 42,9 \\
\hline Paisaje lejano a la vivienda & 2 & 12.5 & 0,0 & 50,0 & 50,0 & 0,0 & 0,0 \\
\hline Desde la perspectiva del cambio climático & 76 & 100.0 & 19,7 & 6,6 & 7,9 & 6,6 & 59,2 \\
\hline $\begin{array}{l}\text { Relaciona los peligros naturales con el cambio } \\
\text { climático } \\
\text { No relaciona los peligros naturales con el } \\
\text { cambio climático }\end{array}$ & $\begin{array}{r}70 \\
6\end{array}$ & $\begin{array}{r}92.6 \\
7.4\end{array}$ & $\begin{array}{r}21,4 \\
0,0\end{array}$ & $\begin{array}{r}2,9 \\
50,0\end{array}$ & $\begin{array}{r}4,3 \\
50,0\end{array}$ & $\begin{array}{l}7,1 \\
0,0\end{array}$ & $\begin{array}{r}64,3 \\
0,0\end{array}$ \\
\hline
\end{tabular}


Tabla 4. Continuación

\begin{tabular}{|c|c|c|c|c|c|c|c|}
\hline & $\begin{array}{c}\text { Total } \\
\mathrm{N} \\
\text { (\% por } \\
\text { columna) }\end{array}$ & \begin{tabular}{|c|} 
Elementos \\
naturales \\
no \\
alterados \\
(\% por \\
filas)
\end{tabular} & \begin{tabular}{|c|} 
Presencia \\
mínima \\
de \\
elementos \\
antrópicos \\
(\% por \\
filas)
\end{tabular} & \begin{tabular}{|c|} 
Elementos \\
naturales y \\
antrópicos \\
en misma \\
proporción \\
(\% por \\
filas)
\end{tabular} & $\begin{array}{c}\text { Presencia } \\
\text { importante } \\
\text { de } \\
\text { elementos } \\
\text { antrópicos } \\
\text { (\% por } \\
\text { filas) }\end{array}$ & $\begin{array}{c}\text { Ausencia } \\
\text { elementos } \\
\text { naturales } \\
\text { (\% por } \\
\text { filas) }\end{array}$ & $\begin{array}{c}\text { Total } \\
\mathrm{N} \\
\text { (\% por } \\
\text { columna) }\end{array}$ \\
\hline $\begin{array}{l}\text { Desde la perspectiva de las propuestas } \\
\text { ambientales }\end{array}$ & 6 & 100.0 & 0,0 & 0,0 & 66,7 & 33,3 & 0,0 \\
\hline Participación comunitaria & 4 & 71.4 & 0,0 & 0,0 & 50,0 & 50,0 & 0,0 \\
\hline Educación y concienciación ciudadana & 2 & 28.6 & 0,0 & 0,0 & 100,0 & 0,0 & 0,0 \\
\hline Participación en planificación urbana & 0 & 0.0 & 0,0 & 0,0 & 0,0 & 0,0 & 0,0 \\
\hline Total & 160 & 100.0 & & & & & \\
\hline
\end{tabular}

Nota: Información obtenida a través de la interpretación y discusión de imágenes de los grupos focales.

Fuente: elaboración propia

Con respecto al ejercicio de mapas metales aplicados a las personas mayores participantes, se obtuvieron 16 mapas temáticos, cuya simbología propició un conocimiento de la imagen que ellos tienen del área de estudio, su paisaje natural cotidiano, así como de sus principales elementos (Lynch, 1960).

Figura 13. Zonificación de elementos del paisaje natural cotidiano, que definen la identidad ambiental de las personas mayores. Colonia Olinalá y Parque Nacional Cumbres, municipio de San Pedro Garza García, Nuevo León, 2014. Mapa sintético

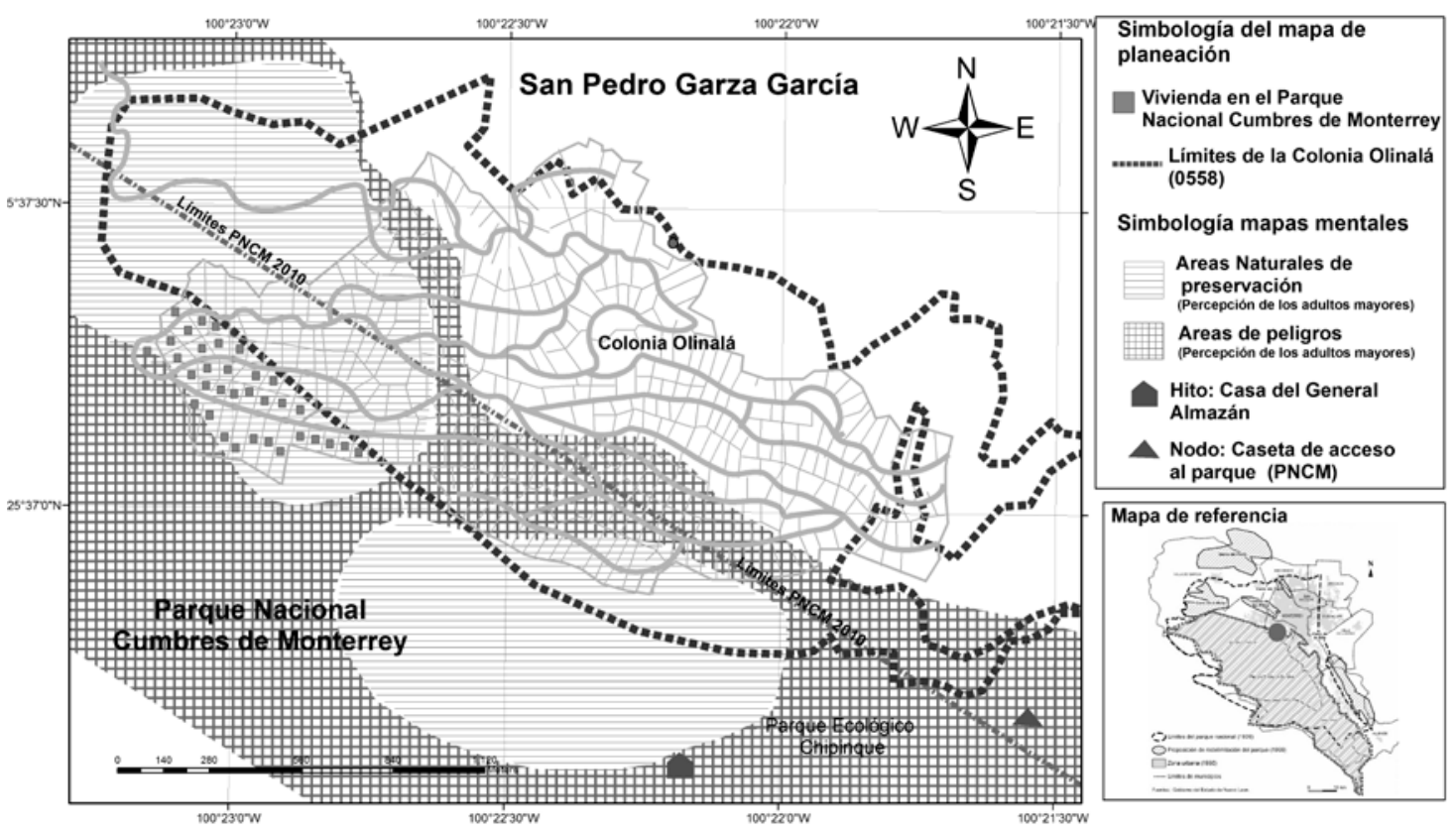

Fuente: elaboración propia a partir de la información combinada de los métodos de fotovoz y mapas mentales 
En relación a los senderos, los adultos mayores identificaron las principales calles y carreteras que conducen al parque natural; sin embargo, no fueron representados los caminos y veredas, ya que son percibidos como peligrosos por su orografía accidentada y por el riesgo de sufrir caídas o afectaciones por deslaves de tierra y rocas. Por su parte, los bordes o límites del parque nacional se determinaron a partir de los recuerdos que ellos tenían de la sierra, comprendiendo una extensión superior a los límites actuales del Parque Nacional Cumbres. Asimismo, entre los hitos destacados sobresale el "Monumento a la $\mathrm{M}^{\prime}$ ", un plegamiento anticlinal de la Sierra en el parque nacional y repoblado con bosques de pino y encinos de la región; la Casa del General Almazán, localizada en el interior del parque y dentro del bosque; y la actual Caseta de entrada al Parque Ecológico Chipinque. A continuación, en las secciones se destacó el área de viviendas que se habían construido en el parque nacional y que representa una amenaza para la conservación de la naturaleza, así como un área caracterizada por la recurrencia de peligros naturales (inundaciones y deslaves). Por último, entre los nodos destacaron algunos puntos viales, que los fines de semana se vuelven conflictivos por el aumento del tráfico de vehículos y la llegada de visitantes al parque nacional (Figura 13).

Por último, mediante un Sistema de Información Geográfica, se procedió a realizar un mapa de zonificación del paisaje natural cotidiano del Parque Nacional Cumbres, desde la perspectiva de la identidad ambiental y el envejecimiento saludable en el lugar, combinando información de los mapas metales y del método de fotovoz.

Los resultados de la zonificación indican que la distribución de los elementos del paisaje natural a proteger está vinculada a la localización de sus lugares cotidianos próximos y frecuentados. También, la participación comunitaria de los adultos mayores se relacionó con el apego al lugar y las experiencias vividas (recuerdos y vivencias), favoreciendo la conectividad con la naturaleza y la realización de actividades en su entorno cotidiano, a través de propuestas ambientales (Ryan et al., 2010; Young et al., 2010; Gueguen y Stefan, 2014). Así, la zonificación obtenida posibilitó una propuesta de delimitación de los límites del área de estudio, así como de las áreas naturales de especial interés para su conservación y áreas expuestas a peligros naturales, convirtiéndose en una herramienta valiosa para la planificación urbana y la protección de los paisajes naturales cotidianos desde el enfoque de la gerontología ambiental.

\section{Discusión}

Los resultados de la investigación indican que las personas mayores asocian el paisaje natural con un ambiente no alterado por el hombre y con un lugar con alto valor sentimental, donde han tenido experiencias positivas. Así, se señala que los elementos del paisaje natural son parte de su identidad personal, elevando de manera positiva la satisfacción con el entorno cotidiano (Tofle, 2009). También, los atributos ambientales, como el tiempo meteorológico (días soleados y 
lluviosos), condicionan el estado de ánimo de los participantes y, con ello, los resultados esperados (Tabbarah et al. 2000). Igualmente, las personas mayores son sensibles a las variaciones ambientes (clima), lo que estaría relacionado con su vulnerabilidad y progresivo deterioro biológico (SánchezGonzález y Egea, 2011; Somi An et al., 2013). A la par, las interacciones ambientales contribuyen a generar actitudes positivas (esperanza) y negativas (estrés), que afectan la sensibilidad y actividad de las personas mayores en el lugar, condicionando sus oportunidades y capacidades para afrontar los desafíos de la vida cotidiana en el envejecimiento (Werner Whal, y Lang, 2003; Krause, 2004).

En el estudio se plantea la posibilidad de los potenciales efectos beneficiosos de los elementos del entorno natural sobre el envejecimiento saludable en el lugar. Al igual que otras investigaciones (Bedimo et al. 2005; Kaczynsky y Henderson, 2007), se observa que la proximidad y frecuencia al parque natural fomentan las actividades al aire libre y las relaciones sociales entre las personas mayores, contribuyendo a mantener sus capacidades y a generar estilos de vida saludables. De lo cual, se desprende que el paisaje natural puede ser un elemento terapéutico que contribuye a favorecer el envejecimiento saludable en el lugar y la calidad de vida de las personas mayores. Así, la exposición a los elementos naturales del paisaje, como árboles y flores, se asoció con las mejoras en la salud física y psicológica, incrementando los efectos positivos y terapéuticos en la persona mayor (Ryan et al. 2010; Bengtsson y Carlsson, 2013, Gueguen y Estefan, 2014). Del mismo modo, los paisajes naturales favorecen las capacidades de las personas mayores, como funcionamientos cognitivos y físicos, el apego a una comunidad y el deseo de interacción social. Por ello, un entorno saludable debe ser usable, atractivo y estimulante, ya que estos conceptos ejercen efectos positivos en el envejecimiento (Bengtsson y Carlsson, 2013; Sánchez-González y Cortés, 2016). Además, se observa el potencial de los paisajes naturales cotidianos, como ambientes restaurativos y de recuperación, que pueden beneficiar las capacidades, la salud y la calidad de vida en el envejecimiento (Grahn y Stigsdotter, 2003; Milligan et al., 2004).

Otro resultado prometedor del estudio señala la posibilidad de que el paisaje natural cotidiano puede ser un elemento simbólico que contribuye a la identidad ambiental de las personas mayores. Al respecto, las preferencias en el paisaje natural están relacionadas con las experiencias cotidianas, cuestiones estéticas y estados de ánimo de las personas mayores, así como su percepción de seguridad asociada con los estímulos ambientales que promueven la protección contra amenazas (Milligan et al., 2004). Así, los adultos mayores identifican sus paisajes naturales cotidianos con sus recuerdos y vivencias, localizados en los límites del parque y próximos a sus domicilios, y convirtiéndose en espacios de significado (Koelen y Van Den Ban, 2004).

Los factores del paisaje natural cotidiano que determinan la identidad ambiental de las personas mayores, están asociados con la presencia de recuerdos y vivencias, la conservación de la vegetación autóctona, la frecuencia y proximidad al parque, las relaciones sociales y el ocio. De la 
misma forma, el apego a los paisajes naturales cotidianos mantiene el sentido de identidad y continuidad, protegiendo frente a los cambios negativos en el envejecimiento (Rubbinstein y Parmalee, 1992). En la misma línea, los adultos mayores, que se rodean de entornos naturales cotidianos, incrementan sus capacidades y autonomía, dándoles un sentido al lugar (Rowles, 1990; Casakin y Neikrug, 2012). Del mismo modo, el paisaje natural cotidiano es una extensión del hogar $y$, con el paso de los años, se crean lazos afectivos a través de vivencias y recuerdos, siendo un factor determinante en el proceso de envejecer en el lugar. Al mismo tiempo, se genera un sentido de conectividad y pertenencia con el paisaje natural cotidiano, ya que, en él han transcurrido sus vidas, lo que implica importantes emociones asociadas al apego al lugar (Valera y Pol, 1994; Kaaty et al.2007; Sánchez-González, 2009), así como a recuerdos y experiencias (Bundy et al., 2002). Al respecto, la configuración del entorno natural y el bienestar personal de los adultos mayores están ligados al sentido de conexión con la naturaleza, el cual puede ser incrementado a través de la empatía (Mayer y McPherson, 2004; Zhang et al., 2014). Además, se observa cierta predisposición a responder positivamente a elementos naturales del paisaje cotidiano, lo que favorece el bienestar en la vejez (Appleton, 1975; Cheung y Wells, 2004).

\section{Conclusiones}

En las grandes ciudades de América Latina, como Monterrey, se agrava el deterioro ambiental de los parques naturales periurbanos, provocado por peligros antrópicos, como crecimiento urbano no planeado y contaminación atmosférica, y por peligros naturales asociados al cambio climático, como inundaciones y procesos de remoción en masa. Así, la progresiva desaparición de los paisajes naturales vinculados a los parques naturales periurbanos tiene implicaciones devastadoras sobre el envejecimiento saludable en el lugar y la identidad personal de las personas mayores.

Las conclusiones del estudio refuerzan las argumentaciones vertidas por la literatura internacional, sobre la importancia de preservar los entornos naturales por sus implicaciones positivas en el envejecimiento (Takano et al., 2002; Rowles, 2006). Así, las investigaciones están indicando que la identidad ambiental en la vejez está determinada por la interacción, exposición y percepción del paisaje natural cotidiano, que implica el reconocimiento de un lugar concreto (sentirse como en el hogar) (Butz y Eyles, 1997, Peace et al., 2006). También, ésta proporciona confort y bienestar en el envejecimiento, generando sentimientos y actitudes hacia el entorno natural, así como propiciando la integración social (Sugihara y Evans, 2000; Vidal y Pol, 2005; Maas et al., 2009; Falk et al., 2012).

Los resultados permiten plantear la importancia potencial de los componentes naturales en el envejecimiento saludable en el lugar, a través de sus posibles efectos tangibles en la salud, incrementando los valores y sentimientos positivos, y fomentando las actividades cotidianas y, en general, la calidad de vida en la vejez (Maas et al., 2009; Falk et al., 2012). Igualmente, se 
constató que la distribución espacial de los entornos naturales a proteger está asociada a sus lugares cotidianos, que generan un sentido de conectividad y pertenencia, y potencian el bienestar y el envejecimiento saludable en el lugar. Se demuestra, entonces, la hipótesis de partida, al comprobar que el paisaje natural cotidiano es un elemento simbólico que contribuye a la identidad ambiental de las personas mayores, que favorece el envejecimiento saludable en el lugar. Por ello, se plantea la necesidad de incrementar el conocimiento sobre las implicaciones de los paisajes naturales, como elemento terapéutico en la generación de formas activas y pasivas para el bienestar físico y mental en el envejecimiento.

Entre las futuras líneas de investigación que se derivan del estudio está el seguir profundizando en la comprensión de las interacciones ambientales en el envejecimiento saludable en el lugar, a través de la generación de actitudes positivas y del fomento de capacidades de adaptación. Asimismo, es necesario incrementar el conocimiento sobre la percepción y experimentación del paisaje natural próximo, así como sus implicaciones socioespaciales en el envejecimiento saludable en el lugar, a través de la generación de oportunidades y capacidades para afrontar desafíos de la vida de la persona mayor.

La preocupación por el cambio climático ha derivado en dos cuestiones de interés creciente: el incremento de los peligros naturales y la preservación del medio ambiente desde una perspectiva ecológica, a través de la relación de las personas mayores con sus entornos naturales, manifestadas mediante sus comportamientos e identidad ambiental (Clayton, 2003). Ante este inquietante panorama, en el estudio se observa una creciente concienciación sobre la protección del medio ambiente y los retos del cambio climático entre las personas mayores, lo que desmiente la idea de la desvinculación de este grupo sobre los retos climáticos para las futuras generaciones.

Es necesario generar políticas públicas encaminadas al envejecimiento saludable en el lugar a través de potenciar el paisaje natural cotidiano, que favorece la salud física y metal, así como la vida activa e independiente (Williams, 1999; Naaldenberg et al., 2012; Lehning et al., 2013). Del presente estudio se desprende que el contacto directo cotidiano con la naturaleza tiene beneficios importantes sobre el envejecimiento activo, al favorecer la autonomía personal y la realización de actividades de la vida cotidiana, como relaciones sociales, recreación y cuidar jardines, así como potenciar los recuerdos y vivencias. Igualmente, la conservación de los paisajes naturales cotidianos proporciona más seguridad y propicia los encuentros sociales y la empatía con los entornos naturales (Carp, 1980; Hillier y Netto, 2002; Schultz, 2002; Gallagher, et al., 2010), aumentando sus capacidades a través de estrategias proactivas frente a las presiones ambientales. Así, se observa que la proximidad a áreas verdes y bosques alienta las actividades al aire libre, lo que tiene efectos positivos en la salud de las personas mayores (Hyoung y Rodríguez, 1996; Somi An, Lee y Tai Kim, 2013). Al respecto, se mitigan las amenazas a través de las emociones que un lugar vivido genera en el adulto mayor (Davidson y Milligan, 2004). Igualmente, se constata que las 
capacidades de adaptación al entorno están relacionadas con la experiencia espacial y tienen consecuencias en el bienestar de envejecer en el lugar (Rowles, 1983). A su vez, los lugares planeados con una infraestructura verde pueden permitir a las personas mayores tener un envejecimiento saludable en el lugar (Lee et al. 2012; Bengtsson y Grahn, 2012; Lehning et al., 2013). Además, subrayamos la importancia de favorecer la participación de las personas mayores en la planificación gerontológica de las ciudades y en la protección del medioambiente.

Desde el campo multidisciplinar de la Gerontología Ambiental y, especialmente desde la Geografía, surge la necesidad de seguir investigando las implicaciones socioespaciales de los paisajes naturales cotidianos, como elementos simbólicos y terapéuticos, que refuerzan la identidad ambiental y potencian el envejecimiento saludable en el lugar. En los próximos años en América Latina los gobiernos se verán abocados a seguir las pautas que marca la Convención Interamericana de Protección de los Derechos de las Personas Mayores, aprobada por la Organización de Estados Americanos en junio de 2015. Algunos de los derechos a proteger en la Convención tienen que ver con los entornos residenciales, como el derecho a una vivienda digna (art. 25), el derecho a un medio ambiente sano (art. 26), o el de favorecer la participación de las personas mayores en ámbitos comunitarios (art. 8) o políticos (art. 17), ante un escenario complejo de envejecimiento de la población y de cambio climático. Por ello, la construcción de ciudades amigables en la región está unida a la imperiosa necesidad de preservar los paisajes naturales y crear los cauces para potenciar la participación activa de las personas mayores, lo que debe implicar una mayor concienciación y aproximación de los profesionales y gestores de la planificación a las cuestiones relevantes de la gerontología ambiental. Un compromiso con el ambiente natural del que depende, en buena medida, nuestro bienestar y las posibilidades de construir entre todos un lugar de encuentro, sostenible, simbólico y terapéutico, donde envejecer de forma saludable y con el que todos nos podamos identificar. 


\section{Bibliografía}

An, S, Lee, Y, y Tai Kim, J. (2013). The Effect of the Public Exercise Environment on the Physical Activity for the Active Ageing of the Elderly. Indoor and Built Environment, 22(1), 319-331.

Andrews, A., Milligan, C., Phillips, D., y Skinner, M. (2009). Geographical gerontology, mapping a disciplinary intersection. Geography Compass, 3(5), 1641-1659.

Appleton, J. (1975). The Experience of Landscape. Chichester: Wiley.

Bauman, Z. (2005). Identity. Madrid: Losada.

Bedimo, A., Mowen, A., y Cohen, D. (2005). The significance of parks to physical activity and public health. American Journal of Preventive Medicine, 28(2), 159-168.

Bengtsson, A., y Carlsson, G. (2013). Outdoor environments at three nursing homes: qualitative interviews with residents and next of kin. Urban Forestry \& Urban Greening, 12(3), 393-400.

Bengtsson, A., y Grahn, P. (2014). Outdoor environments in healthcare settings: A quality evaluation tool for use in designing healthcare gardens. Urban Forestry \& Urban Greening, 13(4), 878-891.

Birol, A. (2012). Reconstitution of the Place Identity within the intervention Efforts in the Historic Built Environment. En H. Casakin y F. Bernardo (Eds.), The Role of Place Identity in the Perception, Understanding, and Design of Built Environments (pp. 63-77). Danvers: Bentham Science Publishers.

Brown, B., y Perkins, D. (1992). Disruptions in place attachment. En I. Altman y S. Low (Eds.), Place attachment (pp. 279-304). Nueva York: Plenum.

Bundy, A., Murray, E., y Lane, S. (2002). Sensory Integration: Theory and Practice. Philadelphia: F. A. Davis.

Buttimer, A., y Seamon, D. (Eds.) (1980). The human experience of space and place. Nueva York: St. Martin's Press.

Butz, D., y Eyles, J. (1997). Reconceptualizing senses of place: Social relations ideology and ecology. Geografiska Annaler, Serie B, 79(1), 1-25.

Carp, F. (1980). Environmental effects upon the mobility of older people. Environment and Behavior, 12(2), 139-156.

Casakin, H., y Neikrug, S. (2012). Place Identity in the Neighborhood as Perceived by the Elder Residents: Relations with Attachment, Dependence and Place Quality. En H. Casakin y F. Bernardo (Eds.), The Role of Place Identity in the Perception, Understanding, and Design of Built Environments (pp. 107-119). Danvers: Bentham Science Publishers. 
Cervinka, R., Röderer, K., y Hefler, E. (2012). Are nature lovers happy? On various indicators of well- being and connectedness with nature. Journal of Health Psychology, 17(3), 379-388.

Chapa Guerrero, J., Meiburg, R., y Scheteling, K. (1993). Geological Risks in the Sierra Madre Oriental. Monterrey: Universidad Autónoma de Nuevo Leon.

Chawla, L. (1992). Childhood place attachments. En I. Altman y S. M. Low (Eds.), Place Attachment (pp. 63-86). Nueva York: Plenum Press.

Chávez, R., y Sánchez-González, D. (2016). Envejecimiento vulnerable en hogares inundables y su adaptación al cambio climático en ciudades de América Latina: el caso de Monterrey. Papeles de Población, 22(90), 9-42.

Cheung, K., y Wells, N. (2004). The natural environment and human well-being from fractal composition analysis? Journal of Harmonic and Fractal Image Analysis, 1, 76-82.

Clayton, S. (2003). Environmental identity: A conceptual and an operational definition. In S. Clayton y S. Opotow (Eds.), Identity and the Natural Environment (pp. 45-65). Cambridge, MA: MIT Press.

Compán, D., y Sánchez-González, D. (2005). Los ancianos al desván. El proceso de degradación biológica y social de la población mayor del municipio de Granada. Cuadernos Geográficos, 36, 255-274.

CONANP (2006). National Park Cumbres of Monterrey. Conservation and Management Program. México: National Comission of Protected Natual Areas, Ministry of Environment and Natural Resources.

Crang, M. (2005). Qualitative methods: there is nothing outside de text? Progress in Human Geography, 29(2), 225-233.

Crompton, T., y Kasser, T. (2011). Meeting Environmental Challenges: The Role of Human Identity. Surrey: World Wide Fund for Nature-WWF.

Cuba, L., y Hummon, D. (1993). A place to call home: Identification with dwelling, community and region. The Sociological Quarterly, 34(2), 111-131.

Davidson, J., y Milligan, C. (2004). Embodying emotion sensing space: introducing emotional geographies. Social \& Cultural Geography, 5(4), 523-532.

Deplege, J., Stone, R., y Bird, W. (2011). Can natural and virtual environments be used to promote improved human health and wellbeing? Environmental Science \& Technology, 45(11), 4660-4665.

Donno, J., Webb, J., y Richardson, B. (2010). The relationship between environmental activism, proenvironmental behavior and social identity. Journal of Environmental Psychology, 30(2), 178-186. 
Dunham-Jones, E., y Williamson, J. (2009). Retrofitting Suburbia: Urban Design Solutions for Redesigning Suburbs. Hoboken, NJ: Wiley.

Dutcher, D. D., Finley, J. C., y Luloff, A. E. (2007). Connectivity with nature as a measure of environmental values. Environment and Behavior, 39(4), 474-493.

Egen, M., y Rose, G. (2012). The Sensory Experiencing of Urban Design: The Role of Walking and Perceptual Memory. Urban Studies, 49(15), 3271-3287.

Epstein, I., Stevens, B., Mckeever, P., y Baruchel, S. (2006). Photo Elicitation Interview (PEI): Using photos to Elicit Childrens Perspectives. International Journal of Qualitative Methods, 5(3), 1-11.

Falk, H., Wijk, H., y Pearsson, L. (2012). A sense of home in residential care. Scandinavian Journal of Cargin Sciences, 4(27), 999-1009.

Feather, N. (1972). Values, valences, expectations and actions. Journal of Social Issues, 48(2), 109-124.

Gallagher, N., Gretebek, K., Robinson, J., Torres, E., Murphy, S., y Martyn, K. (2010). Neighborhood factors relevant for walking in older, urban, African American adults. Journal of Aging and Physical Activity, 18(1), 99-115.

Garvin, T., Nykiforuk, C. I. J., y Johnson, S. (2012). Can we get old here? Seniors perception of seasonal constraints of neighbourhood built environment in a northern winter city. Geografiska Annaler: Series B, 94(4), 369-389.

Godfrey, M., Townsend, J., y Denby, T. (2004). Building a Good Life for Older People in Local Communities: The Experience of Ageing in Time and Place. York: Joseph Roundtree Foundation.

Grahn, P., y Stigsdotter, U. (2003). Landscape planning and stress. Urban Forest. Urban Greening, 2 (1), pp. 1-18.

Gueguen, N., y Stefan, J. (2014). Green Altruism: Short Immersion in Natural Green Environments and Helping Behavior. Environment and behavior, July, 1-19. doi: 10.1177/0013916514536576.

Gustafson, P. (2001). Meanings of place: Everyday experience and theoretical conceptualizations. Journal of Environmental Psychology, 21(1), 5-16.

Harper, D. (1994). On the authority of the image: visual methods at the crossroads. En N. K. Denzin y Y. S. Lincoln (Eds.), Handbook of Qualitative Research. Thousand (pp. 403-412). Oaks, CA: Sage.

Harper, D. (2002). Talking about Pictures: A Case for Photo Elicitation. Visual Studies, 17(1), 13-26. Hillier, B., y Netto, V. (2002). Society seen through the prism of space: Outline of a theory of society and space. Urban Design International, 7, 181-203. 
Huenchuan, S. (2009). Envejecimiento, derechos humanos y políticas públicas. Santiago de Chile: Comisión Económica para América Latina y el Caribe.

Cho, G. H., y Rodríguez, D. (2014). Location or design? Associations between neighbourhood location, built environment and walking. Urban Study, 20, June. doi: $10.1177 / 0042098014537691$.

INEGI (2010). Censo de Población y Vivienda 2010. Aguascalientes: Instituto Nacional de Estadística y Geografía.

Jackson, T. (2004). Motivating Sustainable Consumption: A Review of Evidence on Consumer Behaviour and Behavioural Change. Report to the Sustainable Development Research Network. Guildford, Surrey: University of Surrey.

Kaaty, G., Bygren, L. O., Pembrey, M., y Sjostsrom, M. (2007). Transgenerational reponse to nutrition, early life circumstance and longevity. European Journal of Human Genetics, 15(7), 784-790.

Kahn, P., Severson, R., y Ruckert, J. (2009). The human relation with nature and techonological nature. Current Directions in Psychological Science, 18(1), 37-42.

Kaplan, R., y Kaplan, S. (1996). The Experience of Nature: A Psycological Perspective. Nueva York: Cambridge University Press.

Kaplan, R., y Kaplan, S. (2003). Health, supportive environments, and the Reasonable Person Model. American Journal of Public Health, 93(9), 1484-1489.

Kasser, T., Ryan, R. M., Couchman, C. E., y Sheldon, K. M. (2004). Materialistic values: Their causes and consequences. En T. Kasser y A. D. Kanner (Eds.), Psychology and consumer culture: The struggle for a good life in a materialistic world (pp. 11-28). Washington DC: American Psychological Association.

Kaczynski, A., y Henderson, K. (2007). Environmental correlates of physical activity: A review of evidence about parks and recreation. Leisure Sciences, 29(4), 315-354.

Kellaher, L., Peace, S., y Holland, C. (2004). Environment, identity and old age: Quality of life or a life of quality? En A. Walker y C. H. Hennessy (Eds.), Growing Older: Quality of life in old age (pp. 60-80). Maidenhead: Open University Press.

Ketelle, D. (2010). The Ground They Walk On: Photography and Narrative Inquiry. The Qualitative Report, 15(3), 547-568.

Koelen, M. A., y Van Den Ban, A. W. (2004). Health education and health promotion. Wageningen: Academic Publishers. 
Krause, N. (2004). Lifetime trauma, emotional support and life satisfaction among older adults. The Gerontologist, 44(5), 615-623.

Knopf, R. C. (1987). Human behavior, cognition, and affect in the natural environment. En D. Stokols y I. Altman (Eds.), Handbook of environmental psychology (pp. 783-825). Nueva York: Wiley.

La Gory, M., y Fitpatrick, K. (1992). The effects of environmental context on Elderly Depression. Journal Aging Health, 4(4), 459-479.

Lalli, M. (1992). Urban-related identity: Theory, measurement, and empirical findings. Journal of Environmental Psychology, 12(4), 285-303.

Laws, G. (1993). The land of old age: society's changing attitudes toward urban built environments for elderly people. Annals of the Association of American Geographers, 83(4), 672-693.

Lee, Y., Yoon, H., Lim, S., y An, S. (2012). Housing Alternatives to Promote Holistic Health of the Fragile Aged. Indoor and Built Environment, 21(1), 191-204.

Lehning, A., Smith, R., y Dunkle, R. (2013). Do Age-Friendly Characteristics Influence the Expectation to Age in Place? A Comparison of Low-Income and Higher Income Detroit Elders. Journal of Applied Gerontology, 15 April, 1-23. doi: 10.1177/0733464813483210

Low, S., y Altman, I. (1992). Place attachment: A conceptual inquiry. En S. Low y I. Altman (Eds.), Place attachment (pp. 1-12). Nueva York: Plenum.

Lynch, K. (1960). The image of the city. Boston, Mass: MIT Press.

Maas, J., Van Dillen, S., Verheij, R., y Groenewegen, P. (2009). Social contacts as a possible mechanism behind the relation between green space and health. Health \& Place, 15(2), 586-595.

Mayer, F., y Mcpherson, C. (2004). The connectedness to nature scale: A measure of individuals feeling in community with nature. Journal of Environmental Psychology, 24(4), 503-515.

Melé, P. (2003). Conflits urbains por la protection de la nature dans une metropole mexicaine. En P. Melé, C. Larrue y M. Rosemberg (Eds.), Conflicts et territoires (pp. 103-117). Tours: Presses Universitaires François-Rabelais, Maison des sciences de l'homme.

Melé, P. (2012): Pour une géographie des conflits urbains de proximité en Amérique Latine. Géocarrefour, 87 (1), pp. 3-13.

Milligan, C., Gatrell, A., y Bingley, A. (2004). Cultivating health: therapeutic landscapes and older people in northern England. Social Science and Medicine, 58(9), 1781-1793.

Mitchell, R., y Phopham, F. (2007). Greenspace, urbanity and health: Relationships in England. Journal of Epidemiology and Community Health, 67(18), 681-683. 
Naaldenberg, J., Vaandrager, L., Koelen, M., y Leeuwis, C. (2011). Aging Populations' Everyday Life Perspectives on Healthy Aging: New Insights for Policy and Strategies at the Local Level. Journal of Applied Gerontology, February 1, 1-23. doi: 10.1177/0733464810397703

Noormohammadi, S. (2012). Essential Human Qualities in Strengthening Place Identity as Expressed in Louis Kahn's Architectural Theory. En H. Casakin y F. Bernardo (Ed.), The Role of Place Identity in the Perception, Understanding, and Design of Built Environments (pp. 22-34). Danvers: Bentham Science Publishers.

Norgaard, K. M. (2006). People want to protect themselves a little bit: Emotions, denial, and social movement non participation. Sociological Inquiry, 76(83), 372-396.

Park, S. H., y Mattson, R. H. (2008). Effects of flowering and foliage plants in hospital rooms on patients recovering from abdominal surgery. HortTechnology, 18(4), 563-568.

Peace, S., Holland, C., y Kellaher, L. (2006). Environment and Identity in Later Life. Maidenhead: Open University Press.

Olivos, P., y Aragones, J. I. (2011). Psychometric properties of the Environmental Identity Scale (EIS). Psychology, 2(1), 15-24.

OMS (2007). Global age-friendly cities: a guide. Ginebra: Organización Mundial de la Salud.

OMS (2016). WHO Global Urban Ambient Air Pollution Database. Ginebra: Organización Mundial de la Salud.

Raymond, E., Grenier, A., y Hanley, J. (2014). Community participation of older adults with disabilities. Journal of Community and Applied Social Psychology, 24(1), 50-62.

Relph, E. C. (1976). Place and Placelessness. Londres: Pion.

Rockeach, M. (1973). The Nature of Human Values. Nueva York: Free Press.

Rodríguez-Rodríguez, V., y Sánchez-González, D. (2016). Approaches to Environmental Gerontology in the Mediterranean Europe and Latin America: Policy and practice on ageing and place. En D. Sánchez-González y V. Rodríguez-Rodríguez (Eds.), Environmental Gerontology in Latin America and Europe. Policies and perspectives on environment and aging (pp. 11-44). Nueva York: Springer.

Rohde, C. L. E., y Kendle, A. D. (1994). Human Well-being, Natural Landscapes and Wildlife in Urban Areas: A Review. Worcester: University of Reading.

Rowles, G. D. (1983). Place and personal identity in old age: observations from Appalachia. Journal of Environmental Psychology, 3(2), 299-313. 
Rowles, G. (1990). Place attachment among small town elderly. Journal of Rural Community Psychology, 11(1), 103-120.

Rowles, G. D., y Watkins, J. F. (2003). History, habit, heart and hearth: On making spaces into places. En K. W. Schaie, H. W. Wahl, H. Mollenkopf y F. Oswald (Eds.), Aging independently: Living arrangements and mobility (pp. 77-98). Nueva York: Springer.

Rowles, G., Oswald, F., y Hunter, E. (2004). Interior living environments in old age. En H. W. Wahl, R. Scheidt y P. Windley (Eds.), Annual Review of Gerontology and Geriatrics: Aging in context socio-physical environments (pp. 167-193). Nueva York: Springer.

Rowles, G. (2006). A house is not a home: But can it become one? En H. W. Wahl, H. Brenner, H. Mollenkopf, D. Rothenbacher y C. Rott (Eds.), The Many Faces of Health, Competence and Well-Being in Old Age: Integrating Epidemiological, Psychological and Social Perspectives (pp. 25 32). Dordrecht: Springer.

Rubinstein, R., y Parmelee, P. (1992). Attachment to place and the representations of the life course by the elderly. En I. Altman y S.M. Low (Eds.), Place Attachment (pp. 139-163). Nueva York: Plenum Press.

Ruby, J. (1995). Secure the Shadow. Death and Photography in America. Cambridge, MA: MIT Press.

Ryan, R., Weinstein, N., Bernstein, J., Brown, K., Mistretta, L., y Gagne, M. (2010). Vitalizing effects of being outdoors and in nature. Journal of Environmental Psychology, 30(2), pp. 159-168.

Sánchez-González, D. (2007). Envejecimiento demográfico urbano y sus repercusiones socioespaciales en México: Retos de la Planeación Gerontológica. Revista de Geografía Norte Grande, 38, 45-61.

Sánchez-González, D. (2009). Contexto ambiental y experiencia espacial de envejecer en el lugar: el caso de Granada. Papeles de población, 15(60), 175-213.

Sánchez-González, D. (2014). Identidad del lugar, envejecimiento y presiones ambientales de la ciudad. Reflexiones desde la gerontología ambiental. En D. Sánchez-González y L. A. Domínguez Moreno (Coords.), Identidad y espacio público. Ampliando ámbitos y prácticas (pp. 141-168). Barcelona: Gedisa.

Sánchez-González, D., y Cortés, M. B. (2016). Espacios públicos atractivos en el envejecimiento activo y saludable. El caso del Mercado de Terán, Aguascalientes, México. Revista de Estudios Sociales, 57, 52-67. 
Sánchez-González, D., y Egea, C. (2011). Enfoque de vulnerabilidad social para investigar las desventajas socioambientales. Su aplicación en el estudio de los adultos mayores. Papeles de Población, 17(69), 151-185.

Schultz, P. (2002). Inclusion with nature: The psychology of human-nature relations. En P. Schmuck y W. P. Schultz (Eds.), Psychology of Sustainable Development. Dordrecht: Kluwer Academic Publishers, 61-78.

Schwartz, S. H. (2006). Basic human values: Theory, measurement, and applications. Revue Française de Sociologie, 47(4), 249-288.

Sprout, H., y Sprout, M. (1965). The ecological perspective on human affairs. Princeton, NJ: Princeton University Press.

Stafford, P. (2009). Elderburbia: Aging with a Sense of Place in America. Santa Barbara, CA: Praeger.

Stedman, R. S. (2002). Toward a social psychology of place. Predicting behavior from place-based cognitions, attitude and identity. Environment \& Behavior, 34(5), 561-581.

Sugihara, S, y Evans, G. (2000). Place Attachment and Social Support at Continuing Care Retirement Communities. Environment and Behavior, 32(3), 400-409.

Tabbarah, M., Silverstein, M., y Seeman, T. (2000). A Health and Demographic Profile of Non institutionalized Older Americans Residing in Environments With Home Modifications. Journal of Aging Health, 12(2), 204-228.

Takano, T., Nakamura, K., y Watanabe, M. (2002). Urban residential environments and senior citizens longevity in mega city areas: the importance of walkable green spaces. Journal of Epidemiology and Community Health, 56(12), 913-918.

Tofle, R. (2009). Creating a Place for Dying: Gerontopia. Journal of Housing for the Elderly, 23(1-2), 66-91.

Valera, S., y Pol, E. (1994). The concept of the social urban identity: An approach between the social psychology and environmental psychology. Anuario de Psicología, 62(1), 5-24.

Vidal, T., y Pol, E. (2005). The appropriation of space: A theorical proposal to understand the bond between the persons and the places. Anuario de Psicología, 36(3), 281-297.

Whal, H. W, y Lang, F. (2003). Aging in context across the adult life: Integrating physical and social research perspectives. En H. W. Whal, R. Scheidt y P. G. Windley (Eds.), Aging in context: Sociophysical environments, Annual Review of Gerontology and Geriatrics (pp. 1-35). Nueva York, Springer. 
Whithmarsh, L., y O'Neill, S. (2010). Green identity, green living? The role of pro-environmental self-identity in determining consistency across diverse pro-environmental behaviours. Journal of Environmental Psychology, 30(3), 305-314.

Williams, A. (1999). Therapeutic landscapes: The dynamic between place and wellness. Maryland: University Press of America Inc.

Yen, I., Fandel, J., Thompson, H., Anderson, L., y Wong, G. (2014). How Design of Places Promotes or Inhibits Mobility of Older Adults: Realist Synthesis of 20 Years of Research. Journal of Aging Health, 30 April, 1-33. doi: 10.1177/0898264314527610.

Young, W., Hwang, K., Mcdonald, S., y Oates, C. (2010). Sustainable consumption: green consumer behaviour when purchasing products. Sustainable Development, 18(1), 20-31.

Zhang, J. W., Howell, R. T., y Lyer, R. (2014). Engagement with natural beauty moderates the positive relation between connectedness with nature and psychological well-being. Journal of Environmental Psychology, 38, June, 55-63. doi:10.1016/j.jenvp.2013.12.013 